\title{
DETRÁS DE LOS PARAMENTOS. ORGANIZACIÓN DE LA CONSTRUCCIÓN EN CERRO BLANCO SUR, UN EDIFICIO TEMPRANO DE LOS ANDES CENTRALES (PERÚ)
}

\author{
BEHIND THE VENEERS. LABOR ORGANIZATION IN CERRO BLANCO SUR, \\ AN EARLY BUILDING OF THE PERUVIAN CENTRAL ANDES
}

\author{
Rafael Vega-Centeno Sara-Lafosse ${ }^{1}$, Américo Santillán² y Alexis Solis Curi ${ }^{3}$
}

\begin{abstract}
Se presentan las evidencias arquitectónicas del sitio Cerro Blanco Sur como punto de partida para una caracterización de sus patrones formales y, sobretodo, para realizar un análisis de su proceso constructivo. El análisis formal de la arquitectura revela patrones comparables con los conocidos complejos arquitectónicos del valle de Casma, llevándonos a expandir las posibilidades de interpretación de las dinámicas regionales durante el período Formativo Temprano. Por otro lado, el registro de los paramentos de muros de más de $80 \mathrm{~m}$ de largo en la estructura del sitio central ha permitido reconstruir parte del proceso constructivo de dicho edificio, contemplando un escenario de construcción de los muros a partir del levantamiento de pequeños segmentos en forma secuenciada; patrón que nos permite contemplar como hipótesis un escenario de pequeñas cuadrillas de trabajadores aportando en forma alternada a la construcción final, no siendo necesario el reclutamiento de grandes contingentes de mano de obra. Se trata de un estudio pionero que abre nuevas perspectivas para entender las dinámicas socio-políticas detrás de los edificios públicos del período Formativo.
\end{abstract}

Palabras claves: período Formativo, patrones arquitectónicos, análisis de paramentos, proceso de construcción.

We describe the architectural evidence of the site Cerro Blanco Sur in order to define its formal patterns and evaluate its construction process. The formal analysis reveals similarities with the well-known early architectural complexes of the Casma Valley thus expanding our perspective on regional dynamics during the Early Formative Period. Also the record of the veneers of 80 meterlong walls allows reconstructing the construction process, figuring a scenario where small segments were built in a sequential mode. Hence, it did not seem to have required large-scale recruitment of labor force, but, rather, small groups of masons who worked in a sequential mode during the construction process. Our analysis provides a pioneer study on Early Formative Period construction processes which opens new perspectives for the understanding of the socio-political dynamics behind the building of public architecture during this period.

Key words: Formative Period, Architectural Patterns, Veneer Analysis, Construction Processes.

Las propuestas para entender las dinámicas sociales y políticas del período Formativo en los Andes Centrales (ca. 2500-200 a.C. ${ }^{1}$ ) se han caracterizado a lo largo del tiempo por colocar a la evidencia arquitectónica como sustento principal de sus interpretaciones, algo entendible dada la magnitud y elaboración que los edificios públicos adquirieron en esta región desde épocas muy tempranas. Sin embargo, este uso recurrente del dato arquitectónico como variable que permita reconstruir desigualdades sociales o poderes centralizados no ha ido de la mano con una búsqueda por conocer los procesos de construcción de dichos edificios. Más allá de descripciones generales sobre técnicas y materiales constructivos, es muy escasa la información sobre la secuencia de actividades involucradas en la construcción, la escala de dichas actividades o su organización y sus implicancias sociopolíticas. Esta escasez de información se explica, al menos parcialmente, por el predominio, dentro de la arqueología andina, de la aproximación "termodinámica" (Trigger 1990, ver más adelante) que asume la existencia de una necesaria o universal "dirección centralizada" en la construcción de edificios públicos.

En ese sentido puede decirse que el estudio de los procesos de construcción de monumentos durante el período Formativo es aún una tarea

\footnotetext{
Pontificia Universidad Católica del Perú, Lima, Perú. fvega@ pucp.edu.pe

Agrupación Familiar La Tierra Prometida, Manzana M, Lote 2, San Juan de Lurigancho, Lima, Perú. daliszlyszlo@ hotmail.com Ministerio de Cultura, Lima, Perú. ubillus2681@gmail.com
} 
pendiente ${ }^{2}$. Con estas preocupaciones, llamó nuestro interés la existencia de un sitio con condiciones singulares para estudiar los procesos constructivos en edificios tempranos, se trata del sitio Cerro Blanco Sur. En este sitio, la exposición de grandes extensiones de muros de contención ofrecía la oportunidad de examinar las técnicas constructivas y sus variantes como ruta para aproximarnos a entender la organización de la construcción del edificio.

El 2006, en el marco del Proyecto Arqueológico Fortaleza (PAF), ocho estudiantes de la Universidad Nacional Mayor de San Marcos, bajo la dirección de los autores, se dedicaron por espacio de tres semanas a registrar los paramentos de los muros del sitio. Dicho registro y su posterior análisis ha permitido aproximarnos a entender las técnicas generales de construcción como la posible organización de la misma y, por otro lado, ha permitido también contribuir a conocer mejor las características del período Formativo Temprano en el valle de Fortaleza y el Sistema de Valles de Pativilca, región en donde el estudio de esta época se encuentra aún en etapa inicial. A continuación presentamos los resultados y sus implicancias en el marco del análisis del dato arquitectónico en arqueología.

\section{Arquitectura Pública y Arqueología}

La modificación del espacio geográfico como producto de la acción humana es y será la expresión más notoria de lo que conocemos como cultura material y, como tal, es uno de los apoyos fundamentales del quehacer arqueológico. Esto se ha hecho particularmente evidente en las propuestas de reconstrucción de realidades sociopolíticas a partir de la evaluación de los edificios comúnmente definidos como arquitectura pública, considerados como las mayores expresiones culturales de los pueblos que las levantaron y, por otro lado, del poder, grandeza $\mathrm{y}$ trascendencia de quienes gobernaron o fueron sepultados en ellos (Gloag 1975).

En la segunda mitad del siglo XX, los edificios públicos adquirieron un protagonismo renovado en las interpretaciones sobre la organización política de sociedades del pasado, pero fue trascendiendo las características estéticas de los mismos al enfatizar el hecho constructivo como expresión de relaciones de poder. Esta aproximación fue elocuentemente sistematizada por Trigger, quien notaba que un edificio público monumental expresaba planificación de gran escala, un alto conocimiento ingenieril y, a la vez, el poder para el reclutamiento y dirección de un significativo volumen de fuerza de trabajo (Trigger 1990:121). La relación entre gobernantes y subordinados en esta perspectiva parte del principio de que las sociedades, conforme van jerarquizándose, van adquiriendo mecanismos de control cada vez más despóticos, dirigiendo el trabajo de las poblaciones subalternas hacia la producción de excedentes o la participación en corveas, entre otro tipo de servicios. Más aún, la participación de campesinos como trabajadores de una obra monumental generaría el doble efecto de glorificar a las clases dominantes y, por otro lado, reafirmar a las clases dominadas en su estatus subordinado (Trigger 1990:125).

En el marco de esta aproximación, desde la arqueología, se abordó el estudio del hecho constructivo como herramienta de medición de los grados de jerarquía o complejidad social, generándose nuevos desafíos metodológicos. En un estudio representativo de esta época, Abrams planteó la necesidad de evaluar la construcción bajo el principio de "gasto de energía" y medir dicho gasto en la obtención de materiales de construcción, su transporte a la zona de construcción, la manufactura de los componentes de la estructura y el acto constructivo mismo (Abrams 1989:54). La medición de dicho acto en unidades del tipo jornada/hombre ayudaría a reconstruir los volúmenes de población involucradas en un proyecto arquitectónico y, así, definir la organización o poder político capaz de movilizar a dicha población (Abrams 1989:60).

Reflexiones posteriores, inspiradas en la obra de autores como Hall (1969), Rapoport (1990) y Hillier y Hanson (1984) han resaltado la importancia de ampliar la perspectiva de estudio del fenómeno arquitectónico hacia aspectos relacionados con el diseño de los edificios, considerando tanto la organización espacial como la experiencia sensorial del espacio construido (Ferguson 1996; Moore 1996; Nielsen 1995; Sanders 1990). De igual forma, se ha desarrollado recientemente una crítica a la premisa de la necesaria y universal dirección centralizada de procesos constructivos de gran escala, poniendo en relieve contextos de participación diversificada y escalonada de pequeñas cuadrillas de trabajadores (Wills 2000) o de trabajadores calificados con prerrogativas muy alejadas de la corvea clásica (Hawass y Lehner 1997). En este contexto, la negociación para el reclutamiento de trabajadores a través de mecanismos de persuasión como la 
organización de festines ha sido recurrentemente citada (Dietler 2001).

Estas consideraciones han sido sintetizadas por Pizzo (2009) para el caso de las construcciones romanas. Su aproximación, sin embargo, puede extenderse a otras realidades. Pizzo propone desarrollar una "arqueología de la construcción", orientada a la reconstrucción de procesos constructivos que busquen identificar el proyecto arquitectónico original, sus etapas de construcción (incluyendo la elección y habilitación del terreno, la adquisición de materias primas, el transporte al lugar de construcción, la instalación de infraestructura de construcción, las tareas constructivas y acabados finales), la homogeneidad o variabilidad de las técnicas constructivas, los errores o ajustes durante la construcción pero, en forma simultánea, elementos concomitantes como la composición de los grupos constructores (en términos de sus condiciones de reclutamiento, procedencia o funciones), la cantidad de mano de obra empleada y los tiempos de realización de las tareas (Pizzo 2009:33, 37 38). Es en la línea de estas consideraciones que nuestro trabajo se circunscribe.

\section{La Arquitectura Pública en el Formativo de los Andes Centrales}

El período Formativo en los Andes Centrales es el escenario del proceso de surgimiento de la complejidad social en este territorio y han sido varios los esfuerzos por subdividirlo en etapas que permitan delinear las trayectorias hacia la complejidad a su interior (p.ej. Burger 1992; Lumbreras 1969, 1989). Más recientemente, Kaulicke $(1994,2010)$ ha propuesto una división en cuatro etapas: Temprana (1800-1100 a.C.), Media (1100-800 a.C.), Tardía (800-500 a.C.) y Final (500-200 a.C.). A esta periodificación, se le puede añadir un Formativo Inicial (2500-1800 a.C.) (Onuki 1999; Shady et al. 2016), previamente definido como Arcaico Tardío. Esta inclusión se debe a la constatación de formas de organización complejas desarrolladas en la segunda mitad del tercer milenio a.C. en contexto de culturas precerámicas.

Como en otras partes del mundo, el estudio del surgimiento de la complejidad social encontró en la arquitectura pública "monumental" el soporte de la mayor parte de sus inferencias y, en la línea de aproximaciones como la reseñada líneas arriba, la presencia de montículos-plataforma de diversa escala o elaboración fueron la base para inferir desigualdades sociales y centralización del poder (p.ej. Haas 1987; Lumbreras 1989; Moseley 1975; Pozorski 1987; Pozorski y Pozorski 1998, Shady et al. 2000). Bajo la premisa del necesario poder centralizado para llevar a cabo un proyecto arquitectónico, los debates sobre el nivel de complejidad de las poblaciones en el Formativo se enfocó en la estimación del volumen de los edificios y, en ocasiones, con mediciones sistemáticas, en su posterior transformación en número de jornada/hombre (p.ej. Pozorski 1980; Ravines 1979; Shady 2000).

En forma alternativa, Burger ha criticado el hecho de que, al asumir el volumen como variable que permita estimar complejidad o grado de jerarquía, se caiga en el supuesto de que los edificios constituyen eventos constructivos únicos. Sus investigaciones en el valle de Lurín ponen en relieve que la mayor parte de edificios (si no la totalidad), fueron el producto de sucesivos eventos constructivos llevados a cabo en lapsos prolongados $\mathrm{y}$, a juicio de este autor, susceptibles de ser llevados a cabo por grupos pequeños de trabajadores, cuyos conocimientos no debían ir más allá del ámbito doméstico o comunal (Burger 2009:22-31). Frente al supuesto de la entidad vertical y centralizada detrás de todo proyecto arquitectónico, Burger pone en relieve la capacidad de organización comunal para emprender la construcción de edificios de naturaleza religiosa (Burger 2009:31-34), abriendo así el debate acerca de la necesaria presencia de una centralización del poder y la autoridad detrás de la arquitectura pública al menos en las primeras etapas del período Formativo.

En nuestra opinión, el debate planteado adolece en la actualidad de registros detallados de los procesos de construcción. Por lo general, se cuenta con información sobre materiales y técnicas constructivas y, en ciertas ocasiones, de fases de construcción al interior de los edificios. Sin embargo, esta información ha sido usada fundamentalmente como herramienta cronológica, no contándose con una evaluación de la secuencia de eventos que Pizzo (2009) propone para entender un proceso de construcción.

Sobre la base de estas preocupaciones, VegaCenteno (2005a) llevó a cabo un estudio de los procesos de construcción en el sitio Formativo Inicial de Cerro Lampay, en el valle de Fortaleza. Allí se pudo registrar una secuencia de actividades que incluían el procesamiento y consumo de 
alimentos al interior de espacios arquitectónicos a ser rellenados, seguidas por la limpieza de los espacios para su posterior relleno con piedras (VegaCenteno 2005a:200-216, 2005b). La repetición de esta secuencia puso en evidencia una serie de eventos constructivos de pequeña escala que, en conjunto, permitieron la cobertura de todo un edificio ceremonial. Se propuso además que las actividades de consumo fueron organizadas por quienes dirigían la construcción y, de esta manera, lograban reclutar mano de obra en una forma análoga a la minka, institución registrada en el mundo andino en el siglo XVI y vigente hasta nuestros días (Vega-Centeno 2005a:320-329). Es importante mencionar que esta modalidad de reclutamiento ha sido sugerida también para etapas posteriores de la historia andina (Moseley 1975; Segura 2001).

Las actividades registradas en Cerro Lampay permitieron entender los mecanismos de reclutamiento y actividades relacionadas con una parte específica de un proyecto arquitectónico como es el rellenado de recintos o plataformas. Sin embargo, no pudo registrarse con el mismo detalle el proceso de construcción de muros, en parte por el excelente estado de preservación de los enlucidos en los mismos, que cubrían los paramentos de piedras y no permitían examinar la estructura de las paredes. En ese sentido, la información que se presentará a continuación permite explorar de forma pionera los eventos de construcción asociados con el levantamiento de muros durante el Formativo, en el contexto de la región definida como Sistema de Valles de Pativilca.

\section{El Formativo en Sistema de Valles de Pativilca}

Kosok (1965:217) definió como Sistema de Valles de Pativilca (SVP) al conjunto de tres cuencas (Fortaleza, Pativilca y Supe) ubicadas a unos $200 \mathrm{~km}$ al norte de la ciudad de Lima, que en la actualidad convergen en el piedemonte costero para formar una planicie fértil de unos $23 \mathrm{~km}$ de extensión (Figura 1). Las investigaciones sobre ocupaciones precerámicas en esta región (p.ej. Ruiz et al. 2007; Shady y Leyva 2003; Shady et al. 2016; Vega-Centeno 2005a), actualmente consideradas como del Formativo Inicial, han revelado que no solo se trata de un área articulada en términos geográficos, sino que además albergó un conjunto de manifestaciones culturales interrelacionadas y con características propias, por lo menos para el tercer milenio a.C.

Hay que resaltar, por otro lado, que fue en esta región donde se llevaron a cabo, por primera vez en la arqueología peruana, excavaciones de un sitio asignable al período Formativo. Se trata de las excavaciones llevadas a cabo por Uhle en el sitio de El Faro, en la franja costera del valle de Supe, registrándose un conjunto de contextos funerarios donde los individuos enterrados aparecían asociados con vasijas de cerámica monócroma de pasta reducida y eventualmente decorada con incisiones. Fueron estos contextos la base sobre la cual Uhle infirió su estapa de "Pescadores Primitivos" previa a la de las "Civilizaciones Protoides" (Uhle 1925). Sin duda, los hallazgos de El Faro se convirtieron en un referente de la primera mitad del siglo XX, hecho que llevó a que fuese re-visitado por Gordon Willey y John Corbett, quienes en 1941 volvieron a excavar allí ampliando la muestra de contextos funerarios con el hallazgo. Los materiales recuperados en dichos contextos comprendían cuentas de hueso y concha, cestas, piruros de cerámica, cuencos y botellas de cerámica con decoración incisa (Willey y Corbett 1954:17-20).

El estudio del período Formativo en esta región, sin embargo, no tuvo continuidad. En la segunda mitad del siglo XX, puede mencionarse la visita de la primera misión de la Universidad de Tokyo al sitio de Huaricanga (hoy conocido como "El Castillo de Huaricanga"), en Fortaleza, donde se identificó un montículo construido con rellenos de piedras envueltos en bolsas de fibras o "shicras" (Ishida 1960:204), patrón observado hace años por Julio C. Tello y Cirilo Huapaya (Huapaya 1977).

La visión del Formativo del SVP se construyó, sin embargo, a partir de las observaciones iniciales de Kosok, quien en 1965 llamó la atención sobre montículos artificiales de notable escala en el valle medio de Supe (Kosok 1965:217-223). El registro de 36 sitios donde destacaban montículos piramidales y plazas circulares hundidas, llevado a cabo por Williams y Merino (1979) permitió una primera sistematización de los patrones arquitectónicos de Supe, llevando a considerarse que se trataba de un desarrollo asignable al período Formativo que, además, contaba con características propias, diferentes a desarrollos vecinos, tanto al norte (Fung y Williams 1977) como al sur (Williams 1980), correspondientes al período Formativo Temprano. La referencia a los sitios mencionados en diversos 


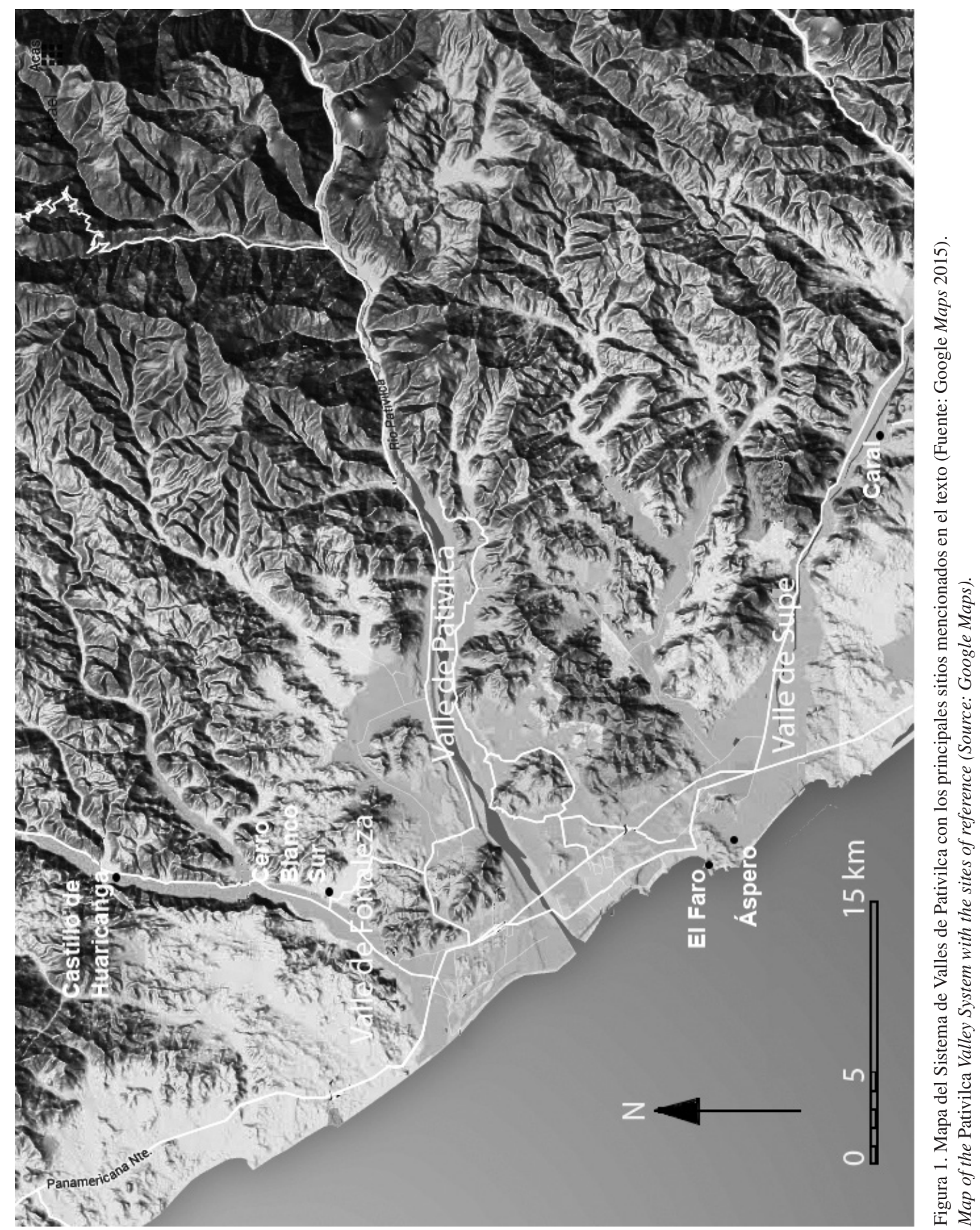


trabajos sobre el periodo Formativo Temprano (p.ej. Burger 1992:230-231; Kaulicke 1994:298-300; Vega-Centeno et al. 1998) evidencia el consenso al que se había llegado con relación a la ubicación cronológica de los mismos.

Resulta claro que este consenso se debía a la importancia que habían adquirido las aproximaciones tipológicas para entender el fenómeno arquitectónico y a la falta de contextos arqueológicos producto de excavaciones. Fue así, que a partir de la segunda mitad de la década de 1990, los trabajos de Shady en el sitio de Caral y, posteriormente, en sitios vecinos (Shady 2001; Shady y Leyva 2003; Shady et al. 2009), junto con las aproximaciones de Haas y Creamer a la problemática de Pativilca (Haas et al. 2004) y las investigaciones de Vega-Centeno en Fortaleza (Vega-Centeno 2004, 2005) revelaron que la mayoría de los supuestos complejos del período Formativo Temprano correspondían, en realidad, a ocupaciones pre-cerámicas, asignadas al Formativo Inicial, llamado hasta hace poco Arcaico Tardío. Esto ha evidenciado la necesidad de replantear nuestro marco de entendimiento sobre el Formativo en el SVP.

El estado de la cuestión actual resulta problemático, en tanto que contamos con evidencias sobre un impresionante y dinámico desarrollo durante el tercer milenio a.C. y los inicios del segundo milenio a.C., que contrastan con una significativa ausencia de las mismas para el período posterior (i.e. Formativo Temprano), hecho que crea un aparente hiatus cultural $\mathrm{u}$ ocupacional para el SVP en el marco de un Área Central Andina en pleno desarrollo. Se hace necesario, por lo tanto, repensar la naturaleza del Formativo Temprano en esta región a partir de una revisión de los contextos existentes que nos permita, por lo menos, delinear posibles trayectorias y futuras investigaciones. En este trabajo intentaremos aportar en esa dirección a partir de evidencias existentes en el valle de Fortaleza.

Como hemos señalado, en este valle ya se había registrado en la década de 1950 la existencia de un conjunto arquitectónico en la zona de Huaricanga (Ishida 1960:204). Este sitio conocido como El Castillo de Huaricanga, fue fechado con una muestra de fibras vegetales en $2040 \pm 40$ a.p. (GaK 109), fecha calibrada entre 1444 a 1056 a.C. Posteriormente, en 1996 se pudo reconocer que el sitio en cuestión estaba compuesto por tres montículos cuadrangulares dispuestos alrededor de un patio, en una típica planta en forma de "U" (Vega-Centeno et al. 1998:228). El registro de este sitio se ha enriquecido con la reciente contribución de Bazán (2010) quien documenta que este conjunto tiene una planta de mayor complejidad, con tres plazas alineadas delante del montículo cuadrangular central (siendo la primera flanqueada por los otros dos montículos). Bazán nota además que al interior de la segunda plaza hay una plaza cuadrangular hundida. Este autor identificó, además, otros alineamientos de muros hacia el lado este de las plazas, que sugieren la existencia de otros espacios (Bazán 2010:26-35). Las características formales del conjunto, la fecha radiocarbónica recogida, así como las características de escasos fragmentos allí encontrados, sugieren a Bazán que se trataría de un conjunto asignable al período Formativo Temprano.

Bazán (2010) plantea, en forma acertada, que la disposición longitudinal de patios delante del edificio central en el Castillo de Huaricanga asemeja bastante al patrón de complejos arquitectónicos ubicados entre los valles de Casma y Huarmey como Sechín Alto, Sechín Bajo, Taukachi Konkán, Pampa de las Llamas - Moxeke, La Cantina, Las Haldas y Mandinga (Álvarez y Espinoza 1997; Fuchs et al 2009; Pozorski y Pozorski 1987; Tello y Mejía 1956) y, en tal sentido, sugiere nuevas dinámicas en las relaciones inter-regionales de las poblaciones del SVP en comparación a lo registrado para el Formativo Inicial.

Las evidencias recuperadas en el Castillo de Huaricanga son, sin duda, sugerentes para considerar la existencia de un conjunto arquitectónico de importancia regional y, posiblemente, con cierto grado de hegemonía en el marco del valle medio de Fortaleza. Un argumento a favor de este escenario es la inexistencia de complejos arquitectónicos semejantes en otras zonas del valle; argumento que, sin embargo, tiene la debilidad de la evidencia negativa. Al respecto, resulta relevante discutir la existencia y rol del sitio Cerro Blanco Sur, ubicado a $17 \mathrm{~km}$ del Castillo de Huaricanga y que, a juzgar por la escala del proyecto constructivo, estaba destinado a ser su par. Esta situación, como veremos más adelante, no llego a darse. Sin embargo, las evidencias arquitectónicas allí registradas han permitido reforzar la idea de contactos con los complejos arquitectónicos casmeños y, sobre todo, han permitido un estudio piloto sobre procesos de construcción, que es materia central del presente trabajo. 


\section{Cerro Blanco Sur}

El sitio arqueológico Cerro Blanco Sur ${ }^{3}$ se encuentra en el distrito de Paramonga, en la provincia de Barranca-Lima. Su localización en coordenadas UTM es 8826483N / 197739E. Se trata de un complejo arqueológico de más de 50 ha de extensión, ubicado en la margen izquierda del río Fortaleza, dentro de una amplia quebrada adyacente en forma transversal a la planicie aluvial del valle (Figura 2).

La quebrada (también llamada Cerro Blanco) tiene un recorrido este-oeste de $5 \mathrm{~km}$ desde las faldas de los cerros donde nace hasta la planicie aluvial, punto en el que llega a tener hasta $3 \mathrm{~km}$ de ancho (en eje norte-sur). A lo largo de este recorrido, la quebrada tiene una pendiente de unos 20 grados caracterizada por una superficie ondulante por efecto de escorrentías y algunos cauces secos.

Las estructuras más prominentes del complejo se encuentran hacia el oeste y han sido definidas como Estructura Arquitectónica 1 (EA 1), 2 (EA 2) y 3 (EA 3). La EA 2 consiste en una plataforma de $31 \times 30 \mathrm{~m}$ asociada con un patio de unos 49 x $31 \mathrm{~m}$, orientada de este a oeste. La plataforma se construyó aprovechando una prominencia del relieve ondulado de la quebrada, cuya cima fue aplanada y los lados fueron reforzados con muros de contención. La EA 3 es una plataforma de 22 m x $18 \mathrm{~m}$ de área orientada de noroeste a sureste ubicada muy cerca de la EA 2. La estructura de mayor tamaño (y objeto del presente estudio) es sin duda la EA 1, que será descrita en mayor detalle.

En el sector oriental del sitio (quebrada arriba), se encuentran alrededor de 10 áreas niveladas distribuidas de manera irregular en el terreno. Se trata de áreas de $25 \mathrm{~m}^{2}$ en promedio, originadas en el retiro de materiales para obtener superficies planas. Estas áreas aparecen en su mayoría aisladas, con excepción de dos casos, ubicados al sur de este sector, donde las encontramos formando conjuntos de cuatro a cinco terrazas alineadas. Áreas semejantes aparecen al norte del sitio, si bien estas últimas son de mayor tamaño. Como componente especial, destaca un muro de gran escala, de 1,5 $\mathrm{m}$ de ancho, que tiene un recorrido de norte a sur de casi $1 \mathrm{~km}$ de extensión, con un primer segmento en dirección norte-sur y un segmento añadido que, volteando hacia el este, vuelve a tomar curso hacia el sur. No se ha podido definir su límite debido al grado de destrucción del mismo en este sector.
La estructura principal y su carácter de proyecto arquitectónico inconcluso.

La EA 1 está orientada de este a oeste, con un azimut de $257^{\circ}$. Se trata de una estructura arquitectónica compuesta de tres secciones principales (Figuras 3-4). La primera consiste en un conjunto de cuatro muros que definen un polígono trapezoidal de más de $9.000 \mathrm{~m}^{2}$. En el centro del polígono, encontramos un pequeño promontorio rocoso de unos $12 \mathrm{~m}$ de altura (Figura 5). La altura máxima registrada en los muros es de 4,72 m (Figura 6).

La segunda sección corresponde a tres terrazas dispuestas sobre la ladera occidental del cerro que fue previamente aplanada. Las terrazas estaban alineadas en el eje antes señalado y tienen áreas de 32 x 29 m, 26 x 32 m y 23 x 38 m. En el extremo de la tercera terraza, se encontró una terraza menor, de 9 x 7,5 m. El registro de superficie permitió establecer que el desnivel entre terrazas se debió superar con escaleras de dos a tres peldaños que permitían un recorrido ascendente hacia la zona del trapezoide antes descrito. En particular, entre la tercera y segunda terraza hay una pequeña plataforma que orienta el acceso entre una y otra. Fue posible además identificar segmentos de muros al parecer de doble cara en los límites entre las terrazas y al interior de las mismas, que sugieren la posible existencia de estructuras elevadas en sus superficies. Estos segmentos aparecen paralelos al borde de cada terraza y, por otro lado, aparecen en forma transversal en la primera y segunda terraza, sugiriendo las divisiones señaladas anteriormente.

La tercera sección se encuentra al sur de la segunda y corresponde a otro conjunto de cuatro terrazas alineadas con el eje general de la estructura, con áreas de 50 x 38m, 52,5 x 23 m, 54,5 x 23 m y 45,5 x 4,5 m. Existen indicios que en la segunda terraza se construyó una plaza circular hundida. En total, la EA 1 cubre un área de 230 x 125 m, es decir, de cerca de casi tres hectáreas.

La organización del conjunto pone en claro que el espacio culminante era el área correspondiente al área trapezoidal. Sin embargo, lejos de encontrar aquí una esperable estructura piramidal truncada, encontramos el muro encerrando al promontorio. Es importante notar que no se trata de muros de doble cara sino de muros con paramento en un solo lado; algo que correspondería a muros de contención. Por otro lado, la ausencia de un volumen significativo de componentes arquitectónicos colapsados pone en duda la existencia de secciones posteriores. A esto 
536

Rafael Vega-Centeno Sara-Lafosse, Américo Santillán y Alexis Solis Curi

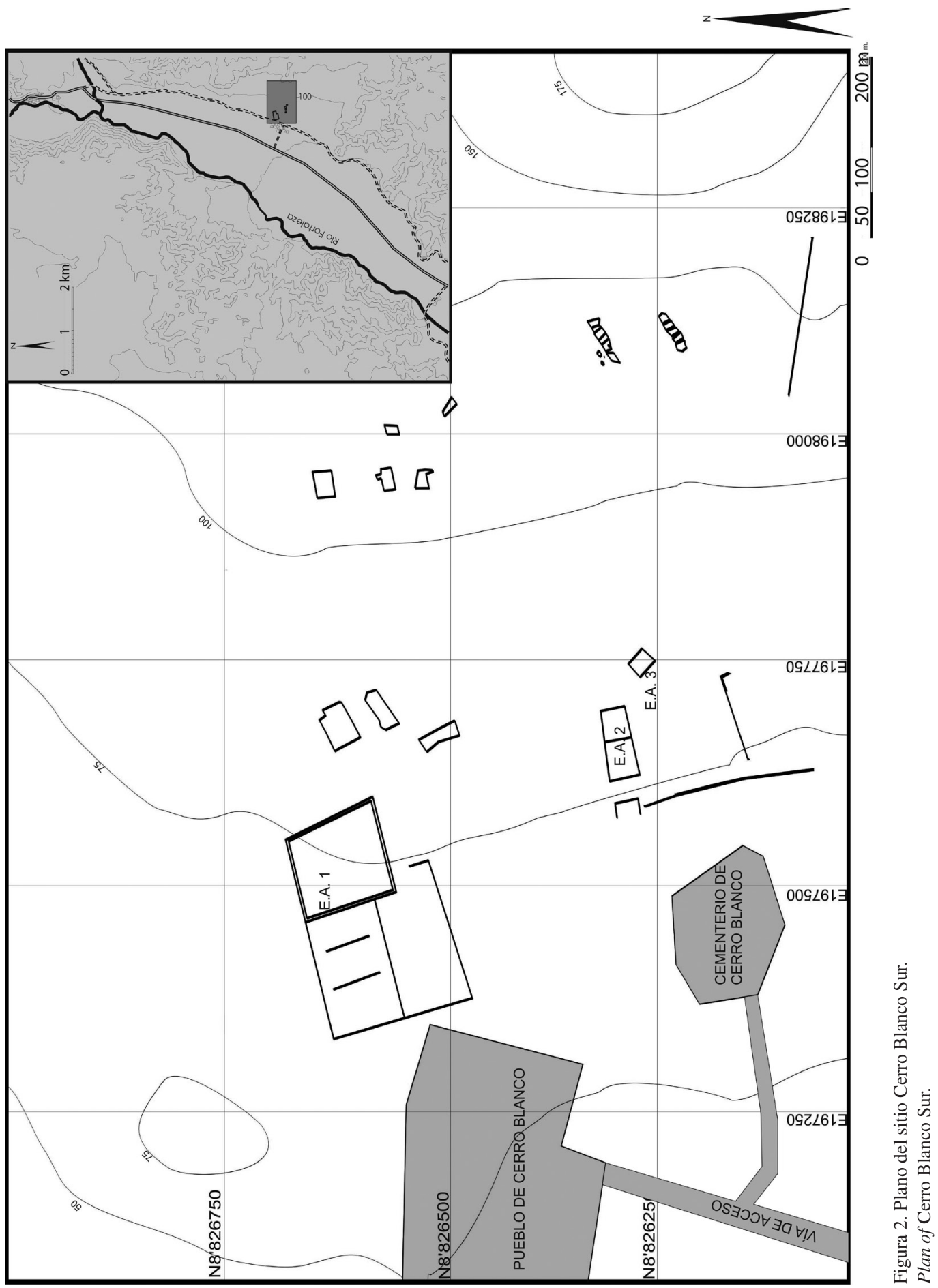



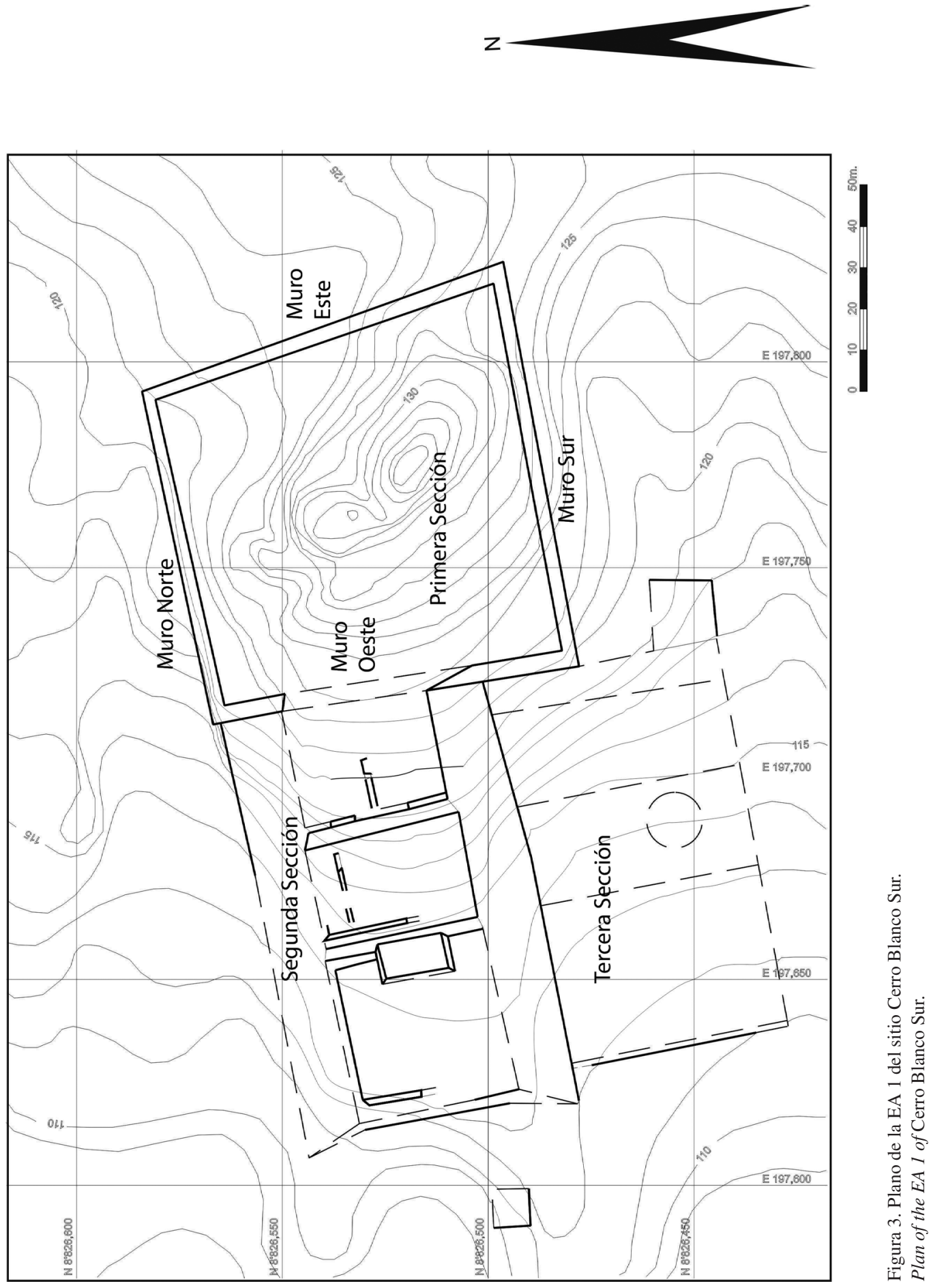


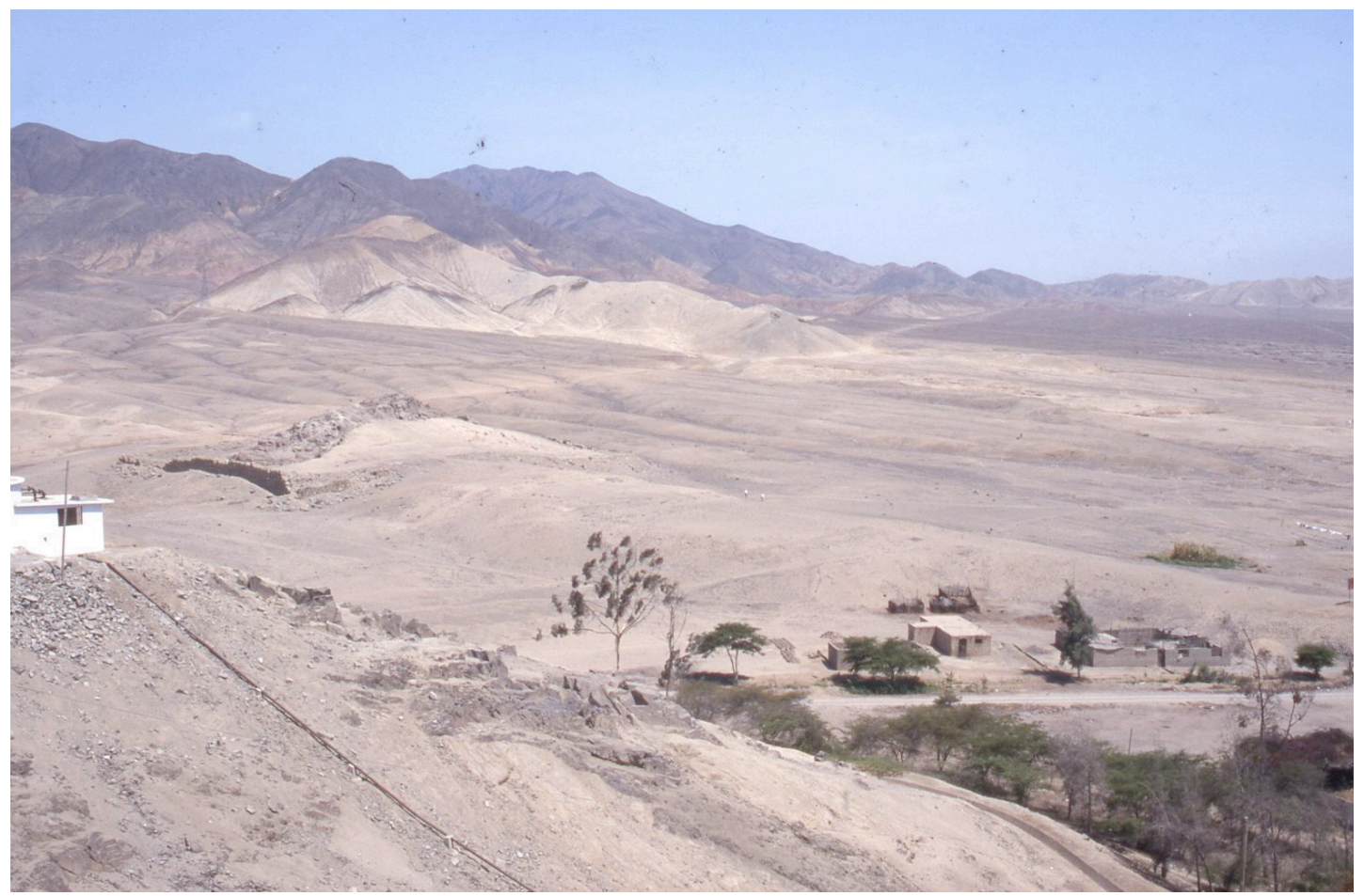

Figura 4. Vista general de la EA 1 del sitio Cerro Blanco Sur. General view of EA 1 of Cerro Blanco Sur.

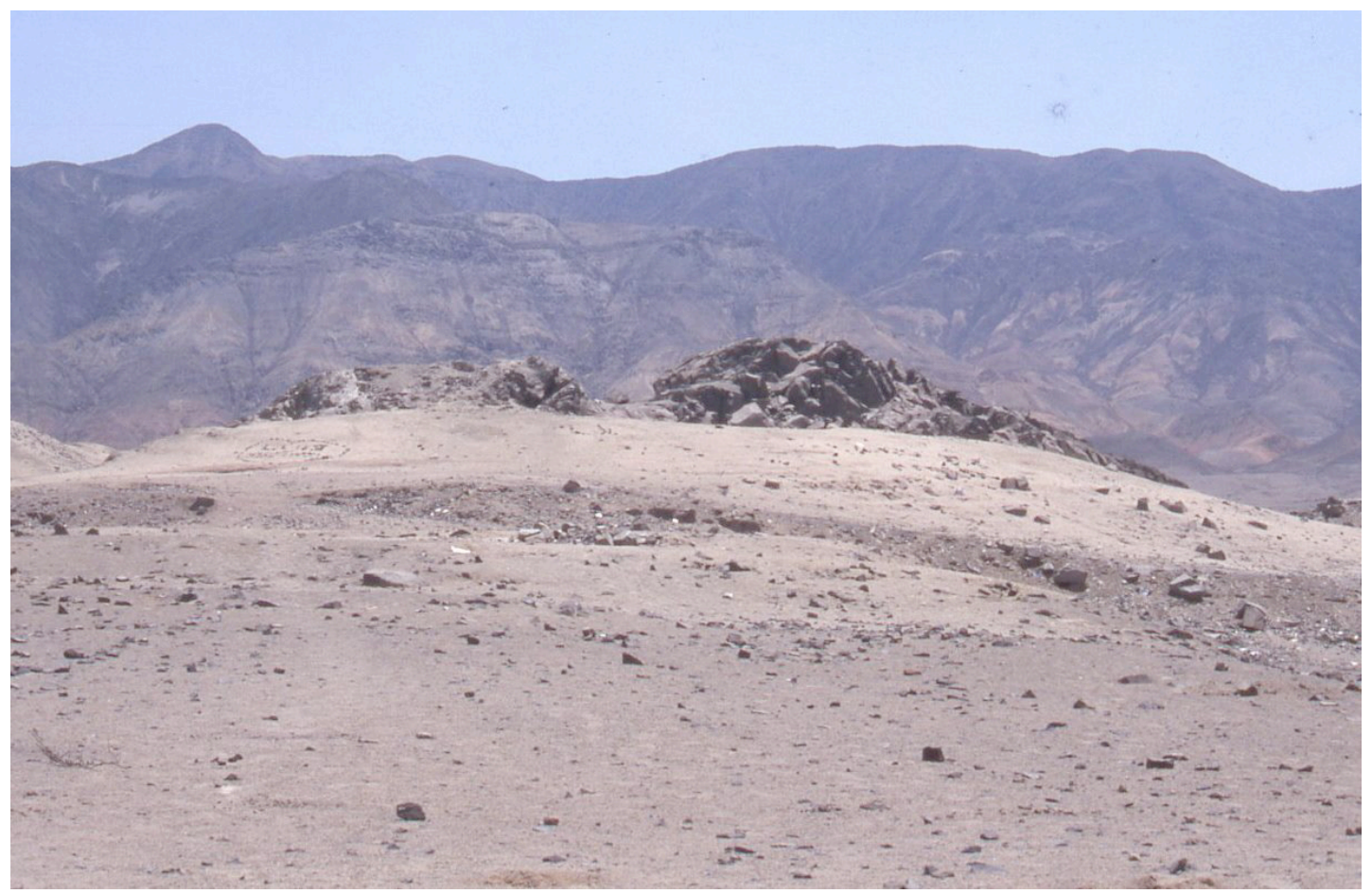

Figura 5. Vista desde el oeste del promontorio ubicado al centro del polígono de la EA 1.

View from the West of the outcrop located in the middle of EA 1 . 


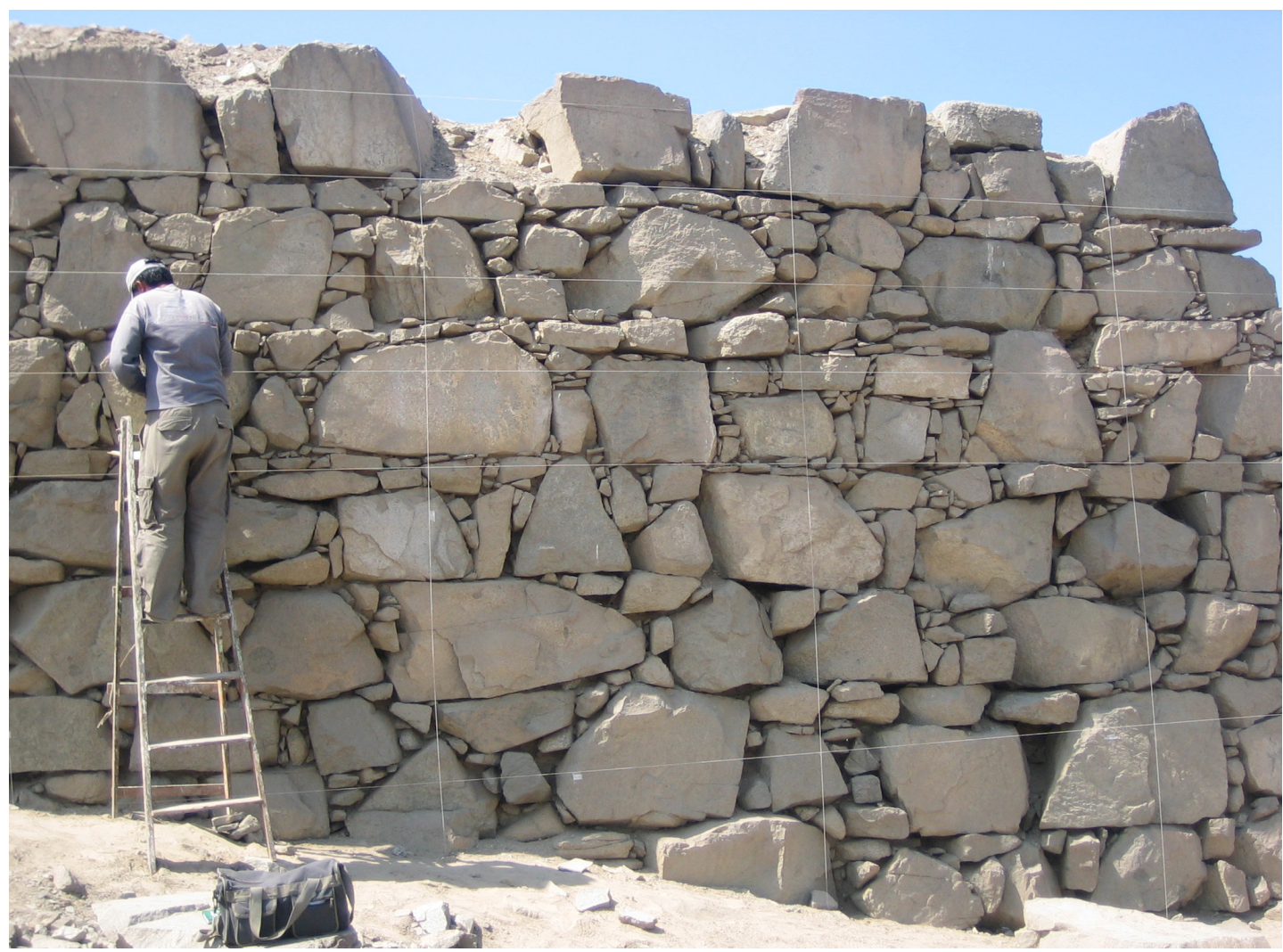

Figura 6. Detalle del muro norte de la EA 1.

Detail of the North wall of EA 1.

debe sumarse el hecho de que el promontorio rocoso ubicado al centro del área trapezoidal aparezca sin cobertura de arena como todos los promontorios de la quebrada. Más aún, fue posible detectar zonas donde se habían extraído bloques de piedra del promontorio, que habría estado cumpliendo funciones de cantera para los constructores de los muros (Figura 7).

Todo esto nos lleva a pensar que se trataría de un ambicioso proyecto arquitectónico que involucraba construir una pirámide trunca de grandes dimensiones que iba a cubrir el promontorio natural el cual, por otro lado, iba siendo reducido conforme se extraían materiales para la construcción. Por razones por esclarecer, este proyecto quedó inconcluso.

Este singular contexto nos brinda una oportunidad para estudiar la organización de la construcción de un edificio de estas características debido a la exposición de importantes segmentos de los muros que comenzaban a formar la estructura. El registro de las características de estos muros será presentado a continuación.

\section{Los muros de Cerro Blanco Sur}

Los muros que cubren al área trapezoidal en la EA 1 de Cerro Blanco Sur son cuatro. Tres de ellos (los muros norte, oeste y sur) tenían uniones en ángulo recto, sugiriendo una planta rectangular. Sin embargo, debido a diferencias en la longitud de los muros norte y sur (Tabla 1), el Muro este tiene un empalme diagonal que genera la planta trapezoidal.

Tabla 1. Dimensiones registradas en los muros de la EA 1. Recorded dimensions of EA 1 walls.

\begin{tabular}{lcc}
\hline Muro & $\begin{array}{c}\text { Longitud } \\
(\mathrm{m})\end{array}$ & $\begin{array}{c}\text { Altura máxima } \\
\text { registrada }(\mathrm{m})\end{array}$ \\
\hline Este & 94,9 & 3,82 \\
Norte & 74,4 & 4,78 \\
Oeste & 89,9 & 2,15 \\
Sur & 96,83 & 3,25 \\
\hline
\end{tabular}




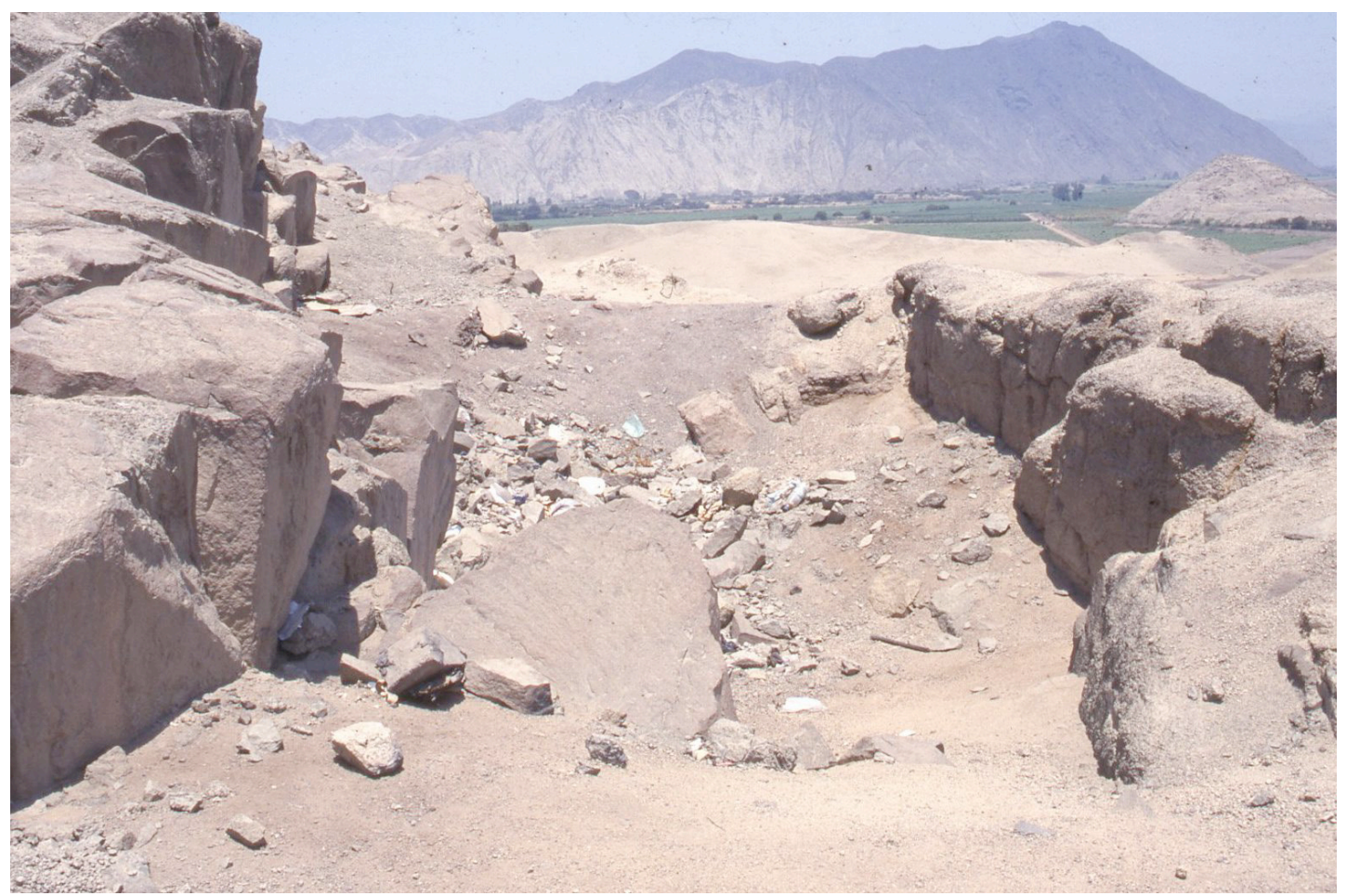

Figura 7. Detalle de zonas canteadas en el promontorio ubicado al centro de la EA 1.

Detail of quarried zones at the outcrop in EA 1.

Se trata de muros construidos en base a piedra canteada y mortero de barro, cuya disposición merece discutirse (Figuras 8 y 9). Es posible distinguir hasta cuatro categorías entre las piedras que interactúan en la construcción. Definimos a estas categorías como: piedras angulares, piedras niveladoras, pachillas ${ }^{4}$ y piedras de soporte.

Las piedras angulares son grandes bloques con caras planas de 0,6 a $0,8 \mathrm{~m}^{2}$ que, dispuestas en hileras, son la base sobre la que se constituye una hilada dentro de la estructura de los muros. Las definimos como piedras angulares ya que las otras piedras se dispondrán en referencia a ellas. Las piedras niveladoras suelen ser bloques de forma alargada, con caras planas de 0,15 a $0,25 \mathrm{~m}^{2}$ que cuentan por lo menos con un borde recto. Estas piedras son colocadas por encima y a los costados de las piedras angulares, para uniformizar el extremo superior de la hilada y crear una superficie nivelada sobre la que se asentarán nuevas piedras angulares. Las pachillas, por su parte, son piedras mucho más pequeñas que son colocadas en los espacios vacíos entre piedras angulares y entre piedras angulares y niveladoras. Por último, las piedras de soporte son piedras de forma irregular y de gran variabilidad de tamaño, que se encuentran por detrás del paramento y conforman la sección interna de los muros (Figura 10a).

El proceso de construcción de muros implicaba la disposición inicial de piedras angulares formando la base de una hilada. Estas piedras contaban con piedras de soporte en la zona posterior. Luego, se colocaban las piedras niveladoras que permitían establecer un nuevo nivel de construcción, culminándose la construcción de la hilada con la ubicación de las pachillas en los intersticios restantes. Se ha podido registrar que las hiladas suelen tener entre 45 a 70 $\mathrm{cm}$ de altura (Figura 10b).

Un detalle importante de la construcción es que en ésta no existen hiladas que cubran toda la extensión del muro, sino que éstas se limitan a formar segmentos que, adosados, conforman un muro. Se ha observado que estos segmentos están por lo general delimitados por un apilamiento de piedras angulares sin presencia de piedras niveladoras, dispuestas en forma inclinada. A veces, sin embargo, el fin de un segmento puede detectarse por un quiebre en la línea de las hiladas (Figura 11). De esta forma, es 


\section{Muro este}

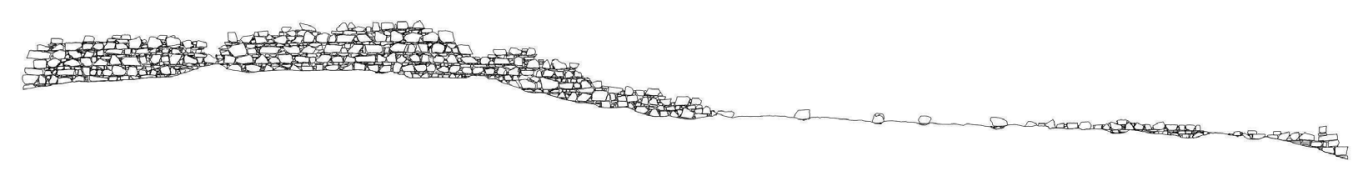

\section{Muro norte}

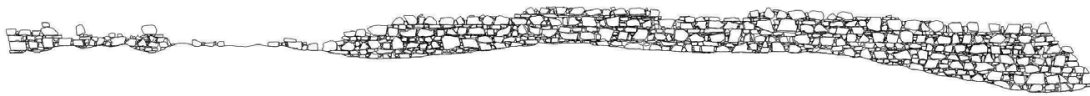

$\begin{array}{lllll}0 & 10 & 20 & 30 & 40\end{array} \quad 50 \mathrm{~m}$

Figura 8. Dibujo de vista frontal de los muros este y norte de la EA 1.

Frontal view of the East and North walls of EA 1.

\section{Muro oeste}

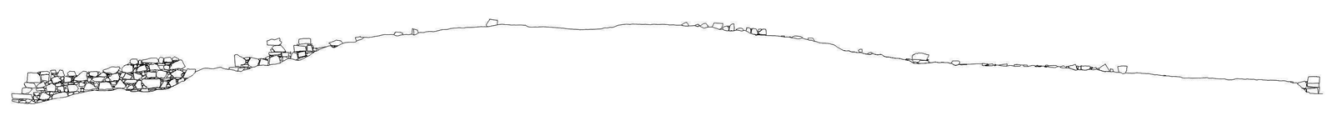

\section{Muro sur}

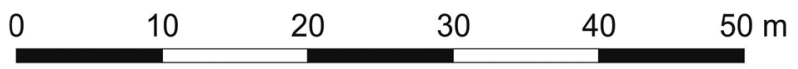

Figura 9. Dibujo de vista frontal de los muros oeste y sur de la EA 1.

Frontal view of the West and South walls of EA 1. 


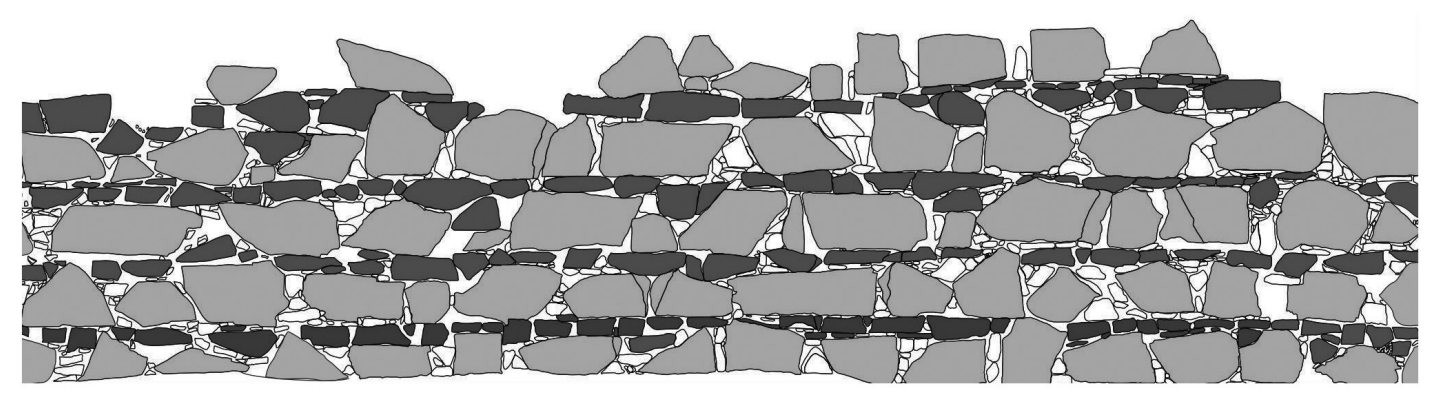

a.

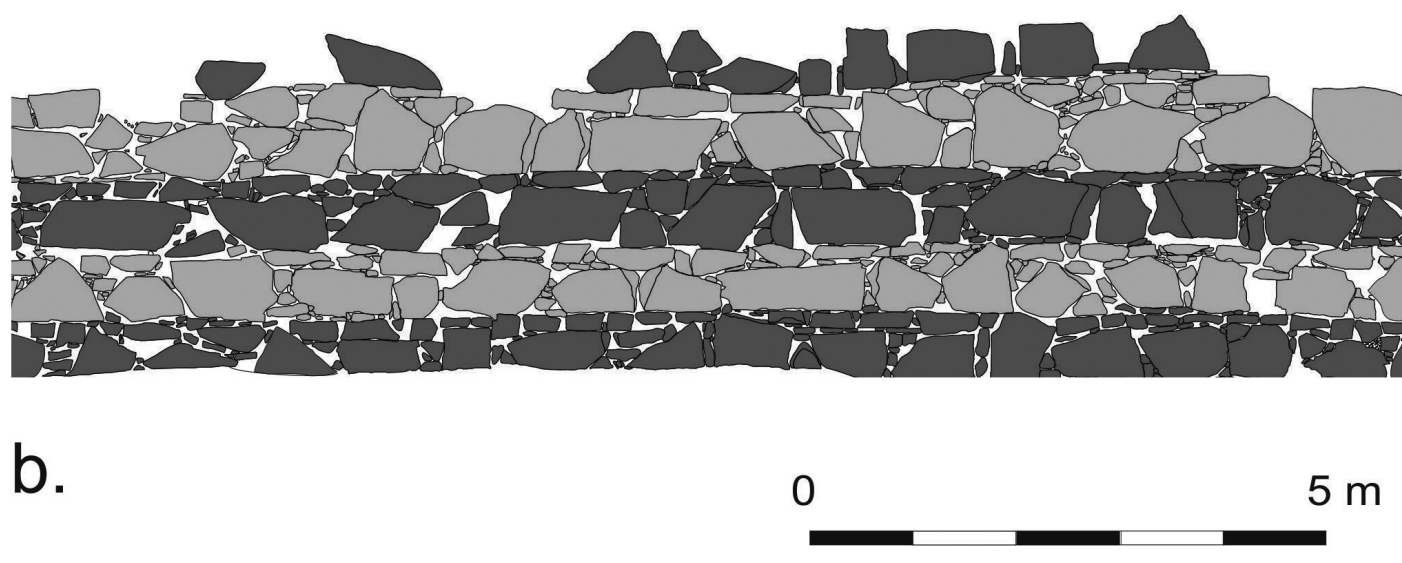

Figura 10. Detalle de vista frontal que ilustra la distribución de materiales constructivos en los muros. (a) Diferenciación de piedras angulares (color gris claro) y piedras niveladoras (color gris oscuro). (b) Diferenciación de hiladas en el mismo segmento. Detail showing the distribution of construction materials in the walls. (a) Indicating angular stones (light gray) and leveling stones (dark gray), (b) Indicating rows within the same segment.

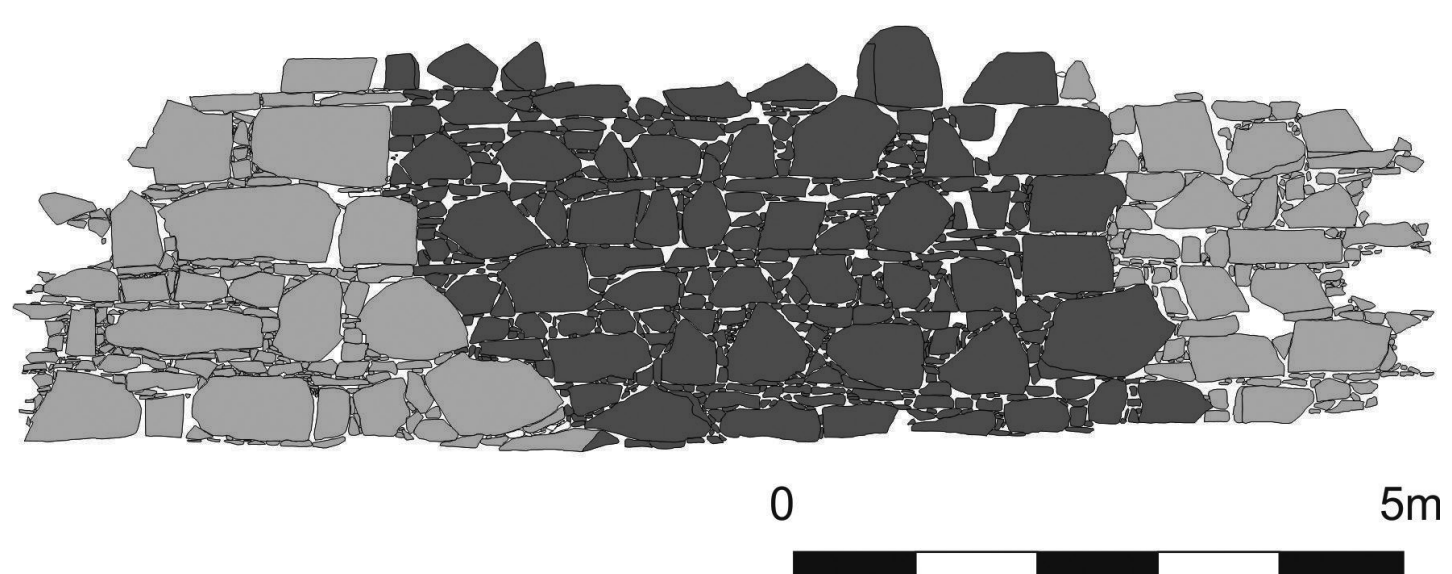

Figura 11. Detalle de vista frontal que ilustra la unión de segmentos. Detail of segment joints. 
posible distinguir tres tipos de segmentos: primarios, secundarios y terciarios.

Los segmentos primarios son aquellos que se construyen sin puntos de apoyo y suelen tener dos apilamientos de piedras dispuestas en dirección opuesta, dándole al segmento una forma trapezoidal. Los segmentos secundarios son aquellos que se asientan sobre los primeros y concluyen con un nuevo apilamiento de piedras. Por último, los segmentos terciarios son aquellos dispuestos entre espacios de secuencias de segmentos. Se apoyan en apilamientos pre-existentes y tienen una forma trapezoidal invertida (Figuras 12 y 13).

El área de los segmentos varía entre los 28 $\mathrm{m}^{2}$ a $50 \mathrm{~m}^{2}$, siendo posible registrar de nueve a 10 segmentos por muro, pudiendo en todos los casos proyectarse la existencia de 14 o 15 segmentos por muro.

Puede observarse, finalmente, un tratamiento particular de las esquinas de los muros. En ellas, es muy escaso el uso de pachillas e inexistente el de piedras niveladoras. Las piedras allí usadas tuvieron un proceso de canteado especial, constituyéndose piezas hexaédricas con por lo menos dos caras planas que permiten definir la línea vertical de la esquina (Figura 14).

A partir de esta descripción, esperamos llegar a comprender el tipo de edificio que se había proyectado y la forma como la construcción se llevó a cabo.

\section{Aproximaciones al proyecto arquitectónico y proceso de construcción en Cerro Blanco Sur}

Las dimensiones registradas en los muros de la primera plataforma de la EA 1 de Cerro Blanco Sur indican que los muros tuvieron hasta por lo menos $5 \mathrm{~m}$ de altura. Teniendo en cuenta la sección vertical de los mismos y la posibilidad de que las secciones inferiores estén cubiertas, consideramos probable que, al ser concluidos los muros pudieron tener hasta $7 \mathrm{~m}$ de altura, estando la base de los mismos acondicionada al relieve en pendiente del terreno (en dirección E-O y N-S) mediante un sistema de aterrazamientos (Figura 15). Señalamos anteriormente que, a juzgar por las huellas de corte en el promontorio, éste habría estado funcionando como

\section{Muro este-Lado sur}

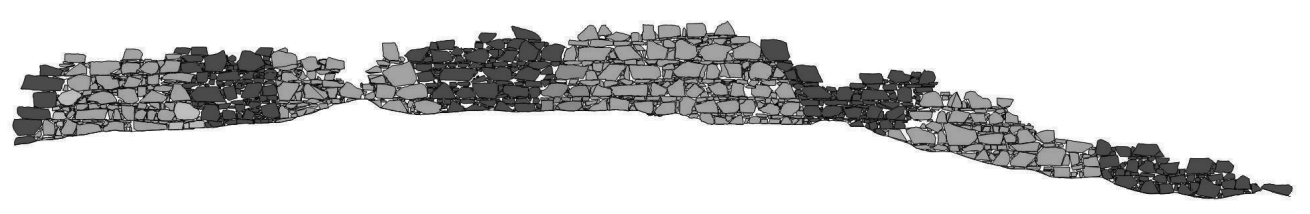

\section{Muro norte-Lado oeste}

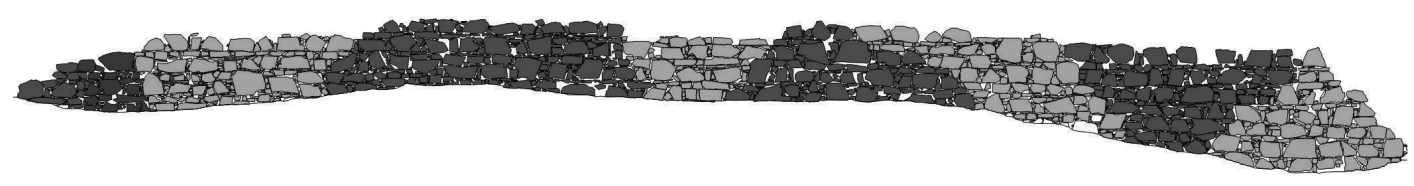

0

10

$20 \mathrm{~m}$

Figura 12. Detalle de vista frontal de los segmentos identificados en los muros este y norte de la EA 1.

Frontal view of identified segments in the East and West walls of EA 1. 


\section{Muro este-Lado sur}

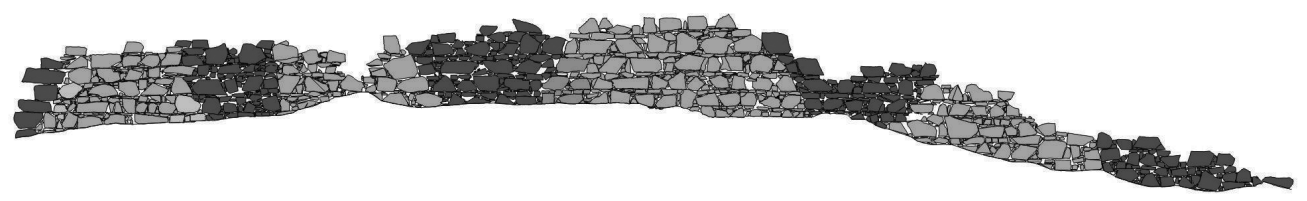

\section{Muro norte-Lado oeste}

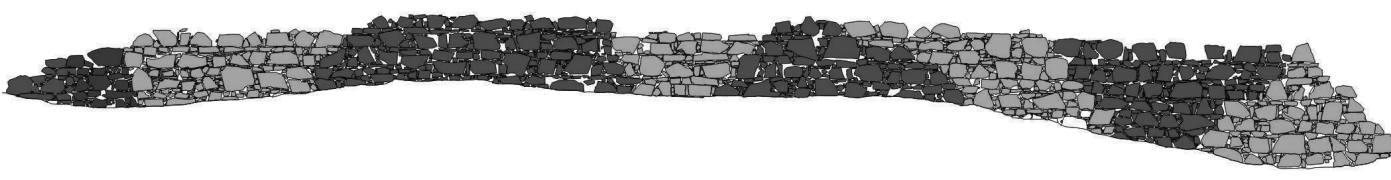

0

Figura 13. Detalle de vista frontal de los segmentos identificados en los muros oeste y sur de la EA 1.

Frontal view of identified segments in the West and South walls of EA 1.

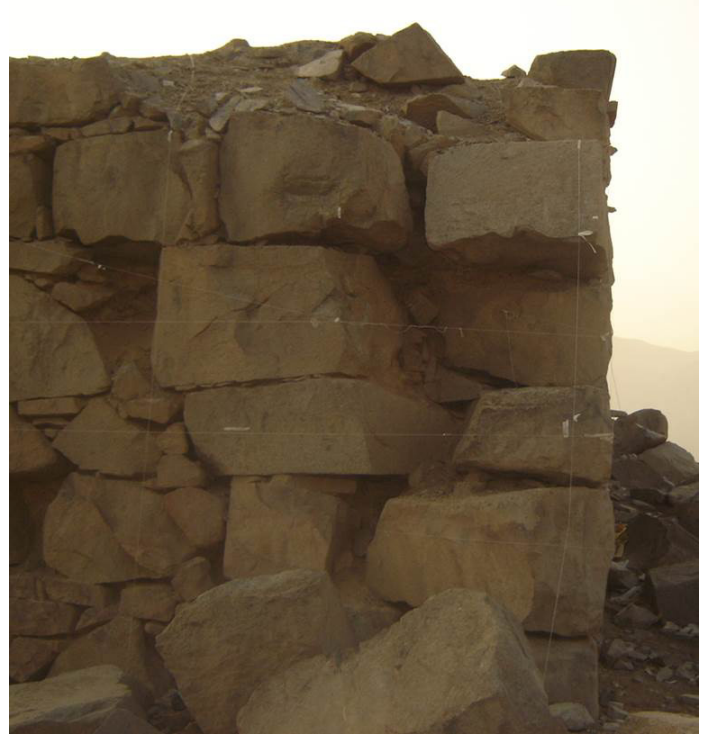

Figura 14. Vista de la esquina suroeste de la EA 1. View of the Southwest corner of EA 1. cantera para la construcción del muro perimetral. Puede especularse, por tanto, que concluidos los muros y rellenada la plataforma que éstos contenían, conforme el promontorio seguía siendo canteado, una segunda plataforma, de unos $5 \mathrm{~m}$ de altura habría sido suficiente para cubrir completamente los restos del promontorio que estaba siendo usado como cantera y, así, culminar la construcción de la estructura.

En relación con la primera plataforma, de acuerdo con la altura estimada, habría sido necesario construir un aproximado de $2.237 \mathrm{~m}^{2}$ de pared, siendo mayor la extensión en el caso de los muros este y sur (Tabla 2).

Partiendo de estos cálculos, es posible estimar de manera preliminar la cantidad de piedras angulares y complementarias requeridas para llevar a cabo la construcción del muro de la primera plataforma en la EA 1. El registro de cuatro extensiones de $4 \mathrm{~m}^{2}$ en diferentes segmentos seleccionados en forma 

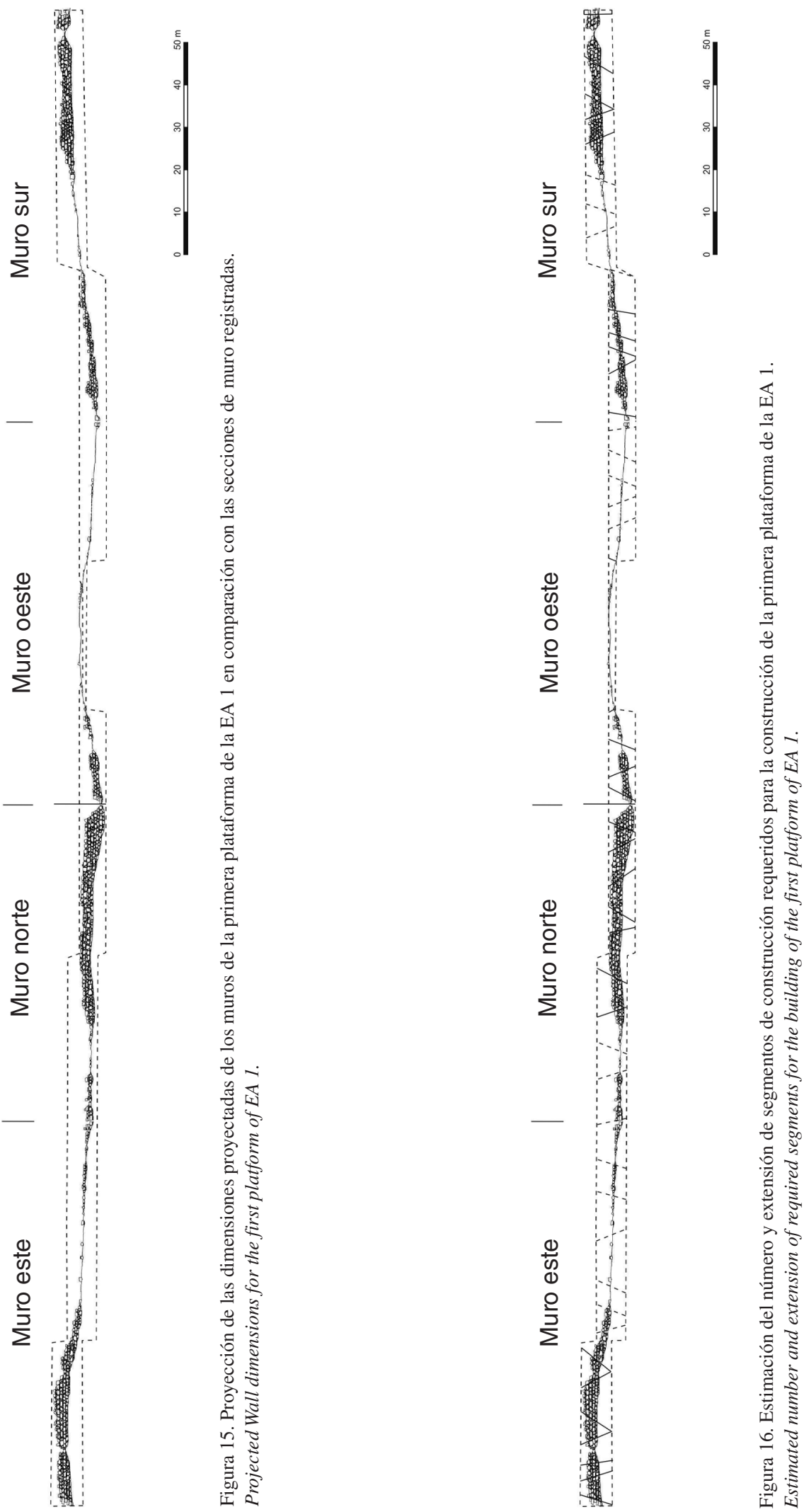
Tabla 2. Proyección de la dimensión de los muros de la EA 1. Projected dimensions of EA 1 walls.

\begin{tabular}{lc}
\hline Muro & $\begin{array}{c}\text { Área de pared proyectada } \\
\left(\mathrm{m}^{2}\right)\end{array}$ \\
\hline Este & 630 \\
Norte & 511 \\
Oeste & 424 \\
Sur & 672 \\
\hline
\end{tabular}

aleatoria en los cuatro muros nos indica el uso de seis a ocho piedras angulares y entre 12 y 16 piedras niveladoras para cubrir dichas extensiones. Esto sugiere que se requirió el uso de entre 3.350 y 4.470 piedras angulares y entre 6.700 y 8.950 piedras niveladoras para la construcción de los cuatro muros. Este impresionante volumen de materiales se debe distribuir de acuerdo a los eventos o tareas constructivas en que se vieron incluidos. Consideramos que estos eventos corresponden a los segmentos antes descritos.

Dentro de los segmentos identificados, se ha podido proyectar una gama variada de dimensiones, siendo por lo general los segmentos primarios los de mayor extensión. Teniendo siempre una forma trapezoidal por sus paredes inclinadas, estimamos que los segmentos primarios pudieron cubrir hasta 60 y $68 \mathrm{~m}^{2}$ de pared. Esto sugiere que, de acuerdo con los cálculos de materiales empleados antes descritos, los segmentos primarios de mayor tamaño contarían con 90 a 140 piedras angulares y entre 180 a 270 piedras niveladoras.

Como hemos mencionado, la construcción comenzaba con los segmentos primarios, cuya extensión a la base oscilaba entre los 10 a 15 $\mathrm{m}$, existiendo una distancia similar entre ellos. Posteriormente, se procedía al levantamiento de los segmentos secundarios que, a juzgar por los registros de las paredes conservadas, se construían mayoritariamente a la derecha de los segmentos primarios, pudiendo formar secuencias de hasta dos segmentos de 2 a $5 \mathrm{~m}$ de extensión. Finalmente, al llegar a la altura del siguiente segmento primario, se construía un segmento terciario que completaba la pared.

Siendo cada segmento una tarea constructiva que requería coordinación para la disposición de las piedras y el mortero, podemos considerar que esta tarea se encontraba a cargo de una cuadrilla de albañiles y, si la construcción de los cuatro muros fue simultánea, esta requirió la participación de unas 18 cuadrillas de albañiles, teniendo en cuenta que existen entre cinco a cuatro segmentos primarios por muro (Figura 16). En este escenario, si bien las cuadrillas de albañiles debían compartir ciertas consideraciones sobre alturas y requerimientos técnicos, al estar los segmentos a distancias prudenciales, se convirtieron en espacios de trabajo autónomos en lo que se refiere a la organización interna de labores. Llama la atención por otro lado la existencia posterior de segmentos secundarios. No es imposible que las mismas cuadrillas que participaron de la construcción de los segmentos primarios asumiesen a continuación los segmentos secundarios. Sin embargo, resulta difícil explicar por qué la existencia de ambos y no, simplemente, la continuación de segmentos de mayor extensión. Una explicación sería que, en primer lugar, se trataría de cuadrillas de albañiles relativamente pequeñas que tendrían contribuciones específicas para luego ser relevadas por otras cuadrillas, en un sistema de trabajo rotativo reconocido en registros históricos y, a su vez, planteado para otros contextos arqueológicos en el área andina (p.ej. Moseley 1975). Es importante mencionar que la estimación del número de miembros de una cuadrilla de albañiles debería incluir un análisis más detallado de los requerimientos de la construcción e, incluso, aproximaciones experimentales. De manera tentativa, consideramos que, para la construcción de los segmentos aquí descritos, estos grupos no requerirían un número mayor a 10 personas.

De ser así, para la construcción del muro de construcción de la primera plataforma, estaríamos hablando de la congregación de alrededor de un par de centenares de albañiles agrupados en cerca de 10 cuadrillas. Podría tratarse de personas provenientes de un mismo asentamiento o entorno o bien podría tratarse de albañiles provenientes de diferentes zonas dentro del valle de Fortaleza. En tal sentido, el grado de variabilidad u homogeneidad en la composición de los trabajadores involucrados en la construcción de la primera plataforma de la EA 1 puede estudiarse a partir del análisis de la variabilidad en la forma en que los distintos segmentos fueron construidos. Dicha variabilidad se debería observar en detalles como el espesor de las hiladas de construcción, el tamaño o número de piedras angulares vs. piedras niveladoras, la abundancia relativa de pachillas, entre otros detalles. Dichos cálculos son difíciles de realizar con el registro incompleto con el que 
aún contamos, pudiendo precisarse con la limpieza total de los muros que permita evaluar el proceso de construcción de cada segmento con mayor precisión.

Una observación preliminar, sin embargo, permite notar llamativas diferencias dentro de segmentos relativamente cercanos (Figura 17). En el caso del muro sur, por ejemplo, podemos encontrar segmentos con piedras angulares de tamaños relativamente discretos, acompañados de abundantes pachillas y piedras niveladoras también pequeñas que permiten distinguir nítidamente hiladas de poco espesor. En contraste, dentro del mismo muro, encontramos otros segmentos donde las piedras angulares son de mayor tamaño y, al estar bastante concentradas, ocupan mayor espacio relativo, siendo menor el espacio tanto para las pachillas como para las piedras niveladoras (Figuras 17a-b). En el caso del muro norte, ha sido posible también encontrar diferencias entre segmentos con piedras angulares de gran tamaño acompañados por piedras niveladoras pequeñas vs. otros segmentos donde las piedras niveladoras son de mayor longitud y permiten la identificación clara de las hiladas (Figuras 17c-d). En tal sentido, proponemos a manera de hipótesis que en la construcción de la primera plataforma de la EA 1 se congregó a grupos de albañiles con bagajes técnicos variados que probablemente provinieron de localidades diferentes dentro del valle. Las implicancias de las observaciones e inferencias aquí planteadas son discutidas a continuación.

\section{Proyecto Constructivo y Dinámicas Sociopolíticas. Cerro Blanco Sur en el Contexto de los Andes Centrales}

Las evidencias recuperadas en Cerro Blanco Sur ofrecen elementos para plantear una agenda de

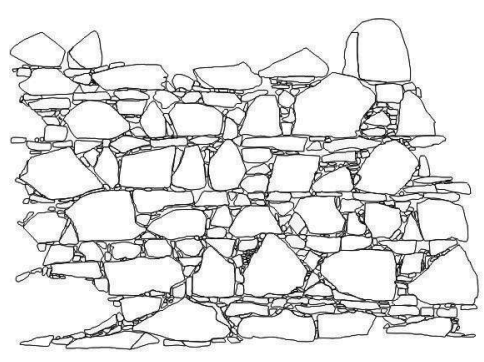

a.

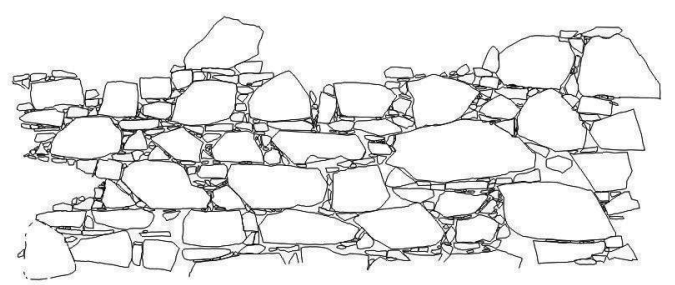

b.

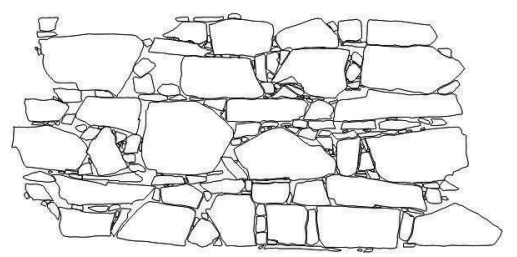

d.

Figura 17. Vista frontal de segmentos de los muros este y norte con diferencias en la disposición de materiales constructivos. (a-b) Son del muro este y (c-d) del muro norte.

Frontal view of segments of the East and North walls showing differences in the distribution of construction materials. (a-b) Correspond to the West wall and $(c-d)$ to the North wall. 
investigación sobre los procesos de construcción que permitieron la existencia de los impresionantes monumentos que caracterizan al Formativo de los Andes Centrales y, a su vez, para expandir el conocimiento puntual del Formativo Temprano en la región del SVP.

En términos regionales, como hemos señalado, los valles de Pativilca han adquirido reciente notoriedad debido a la llamativa concentración de complejos arquitectónicos de gran escala fechados en el tercer milenio antes de Cristo, dentro de lo que se está llamando en la actualidad Formativo Inicial (Onuki 1999), siendo más escasas las evidencias de épocas posteriores.

En el caso de Cerro Blanco Sur, si bien no contamos con evidencia contextual que nos permita asignar con precisión su ubicación cronológica, ciertos elementos nos van a permitir proponer su asignación al Formativo Temprano. El primer elemento surge de la comparación de la técnica de construcción de muros de Cerro Blanco Sur con las técnicas de construcción registradas en sitios del período Formativo Inicial como Caral, Cerro Lampay o Huaricanga Sur, entre otros. En todos ellos, se observa como en Cerro Blanco Sur el uso de piedras canteadas de diferentes tamaños. Sin embargo, no se observa la combinación de piedras angulares y niveladoras para constituir hiladas con cierta regularidad. Esta variabilidad en términos de técnica constructiva puede entenderse como una variabilidad cronológica, toda vez que la misma técnica de piedras funcionales y estructurales parece estar presente en sitios como el Castillo de Huaricanga que, como hemos visto, cuenta con un fechado que lo ubica dentro del Formativo Temprano. El segundo componente se relaciona con el diseño arquitectónico en sí. Cerro Blanco Sur presenta un claro patrón de plataforma aterrazada asociada con una sucesión de patios dispuestos en eje longitudinal, tal como aparece en el Castillo de Huaricanga; patrón que está ausente en los complejos arquitectónicos del Formativo Inicial en la región y que aparece en sitios del Formativo Temprano de los valles de Casma y Huarmey.

A las semejanzas mencionadas hay que añadir también el registro de la construcción por hiladas regulares en segmentos de muros de sitios casmeños como Sechín Alto o Moxeke (Fung y Williams 1977) (Figuras 18-19). En ese sentido, los registros de la modalidad de construcción en Cerro Blanco Sur podrían ser representativos de la forma en que los edificios del Formativo Temprano se estarían construyendo.

Un último elemento es estrictamente contextual y tiene que ver con el hallazgo de un fragmento de cerámica empotrado en el mortero de uno de los muros de la primera plataforma de la EA 1 en Cerro Blanco Sur (Figura 20) que confirma su ubicación cronológica posterior a períodos pre-alfareros.

$\mathrm{Si}$, tal como proponemos, Cerro Blanco Sur se ubica dentro del período Formativo Temprano, debe considerarse cuáles son los factores para que tanto este sitio como el Castillo de Huaricanga estén compartiendo patrones característicos de valles de más al norte. Escenarios de influencias, emulaciones, apropiaciones o, eventualmente, procesos migratorios, son algunas de las posibilidades que se abren para explicar estos patrones compartidos y que investigaciones futuras deberían abordar.

Por otro lado, más allá de consideraciones cronológicas o corológicas, es relevante enfocar el tema del proceso constructivo en sí. En líneas anteriores hemos señalado que son casi nulos los estudios de dichos procesos para las épocas en cuestión. En tal sentido, el registro de construcción secuenciada de Cerro Blanco Sur tiene la novedad (y la debilidad) del hallazgo pionero. Sin embargo, debe notarse que la modalidad segmentaria allí registrada encuentra ciertos paralelos con propuestas hechas para construcciones más tardías, como la Huaca del Sol de Moche (Moseley 1975). Moseley propone que este tipo de construcción segmentaria equivaldría al sistema de la mita presente en los registros históricos del siglo XVI. Un sistema segmentario de construcción fue además propuesto para el sitio de Cerro Lampay, en relación con la colocación de rellenos de plataformas (Ascencios 2009; Vega-Centeno 2005b). Siendo Cerro Lampay del Formativo Inicial y Huaca del Sol del período de Desarrollos Regionales, podemos considerar que la organización segmentaria de la construcción podría estar constituyendo una tradición de larga data dentro de la cual, sin embargo, queda pendiente la tarea de definir sus modalidades y evolución.

Por otro lado, el tipo de organización segmentaria abre la posibilidad de discutir el grado de centralización de la toma de decisiones en el proceso constructivo. $\mathrm{Al}$ respecto, existe ya una discusión en distintas regiones del mundo sobre los problemas derivados de controles altamente centralizados para procesos que involucran 


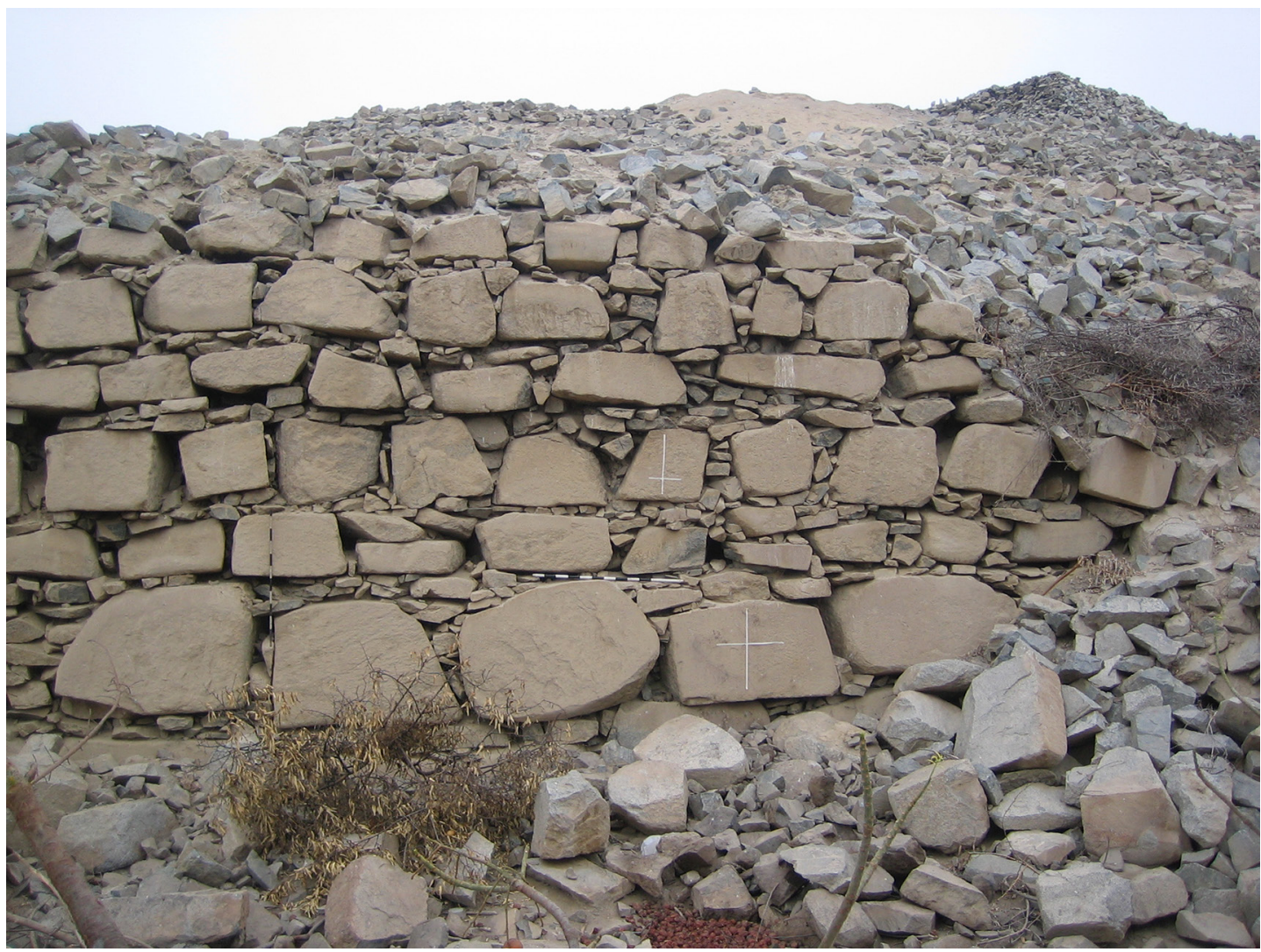

Figura 18. Vista de paramentos del sitio de Sechín Alto.

View of veneers from the Sechín Alto site.

operaciones de tareas múltiples en contraste con la mayor flexibilidad y, finalmente, eficiencia de procesos caracterizados por articulación de segmentos no superpuestos que administran sus tiempos y metas sucediendo y antecediendo la labor de otros segmentos (Wills 2000:37). Si bien esta explicación de tipo funcional para la existencia de una organización segmentaria es plausible, no es necesariamente exhaustiva para entender dicha organización, pudiendo ser ésta el resultado de complejos procesos de negociación entre quienes proyectaron la construcción y quienes eran reclutados para participar en la misma. Los contextos de agasajos previos a las tareas constructivas (Segura 2001; Vega-Centeno 2005b) refuerzan la hipótesis de un escenario con complejos mecanismos de negociación para el reclutamiento de mano de obra en el caso andino. En esa dirección, consideramos que en Cerro Blanco Sur estamos ante un contexto de congregación de grupos pequeños de trabajo, probablemente procedentes de linajes u otro tipo de unidad de parentesco con tareas puntuales programadas en forma secuencial dentro del proceso constructivo. La variabilidad en la disposición de los distintos tipos de piedras entre segmentos nos sugiere bagajes técnicos variados, eventualmente reveladores de procedencias diversas. De esta manera, se propone como hipótesis que una obra de gran escala como la descrita se pudo realizar sin necesidad de la congregación simultánea de grandes contingentes de mano de obra, sino a través de la participación escalonada de pequeños grupos de diferentes asentamientos o comunidades de la región.

No podemos ignorar, finalmente, que este proceso, aparentemente bien concebido y organizado fue, en el caso de Cerro Blanco Sur, un proyecto que quedó trunco. Todo parece indicar que se trataba de la construcción del centro político hegemónico para la sección inferior del valle 


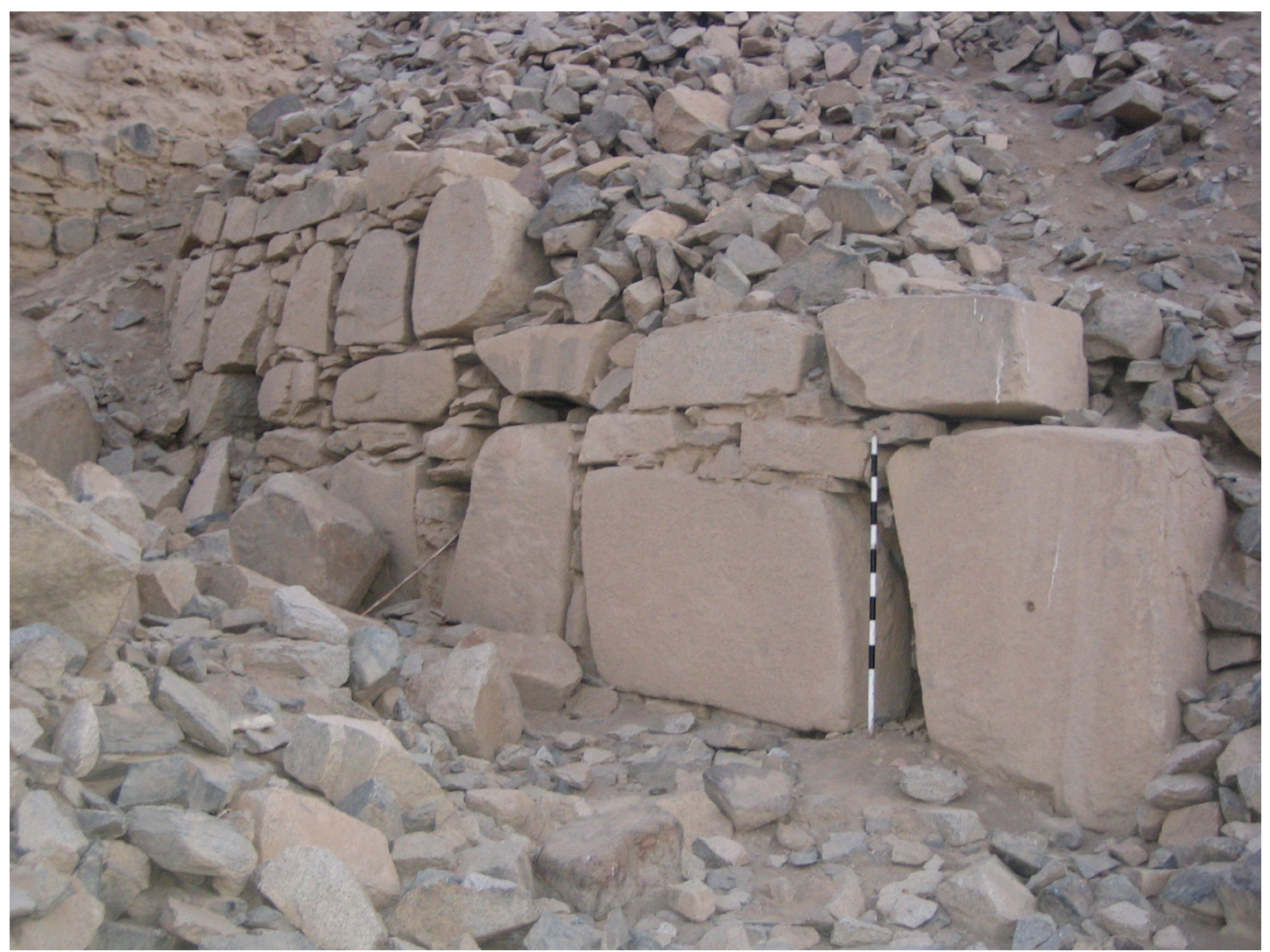

Figura 19. Vista de paramentos del sitio de Moxeke.

View of veneers from the Moxeke site.

medio de Fortaleza. Los factores que llevaron a la interrupción de la construcción deberían ser materia de futuras investigaciones. La posibilidad de que los grupos dirigentes de complejos como el Castillo de Huaricanga, ante la posibilidad de una competencia por la hegemonía del valle, hayan tenido algún protagonismo en todo esto no debería descartarse.

\section{Reflexiones Finales}

La información sobre Cerro Blanco Sur aquí presentada permite una primera mirada en dos direcciones. La primera se relaciona con los procesos de construcción de edificios públicos en las etapas tempranas de la historia de los Andes Centrales. El análisis de la composición de muros y terrazas ha mostrado ser una eficaz aproximación para reconstruir secuencias de actividades y la escala de las unidades de trabajadores participantes. Este tipo de reconstrucciones deberían constituirse, a futuro, en la base empírica que permita evaluar las interpretaciones sobre las implicancias socio-políticas de los procesos de construcción y, eventualmente, replantearlas sobre bases más sólidas.

Desde otra mirada, debe reconocerse, por otro lado, que la reconstrucción aquí presentada es, sin duda, parcial, en tanto que solo aborda las actividades de levantamiento de muros, debiendo estudiarse los procesos de adquisición de materiales (no solo las piedras, sino también el material para los morteros y los rellenos), de habilitación del terreno, de preparación de las terrazas adyacentes, en la línea de lo propuesta por Pizzo (2009). Consideramos que, debido a la naturaleza "inconclusa" del edificio, la posibilidad de poder abordar el estudio de la cadena de actividades, a partir de un estudio de campo que implique excavaciones a escala, es bastante promisoria. 


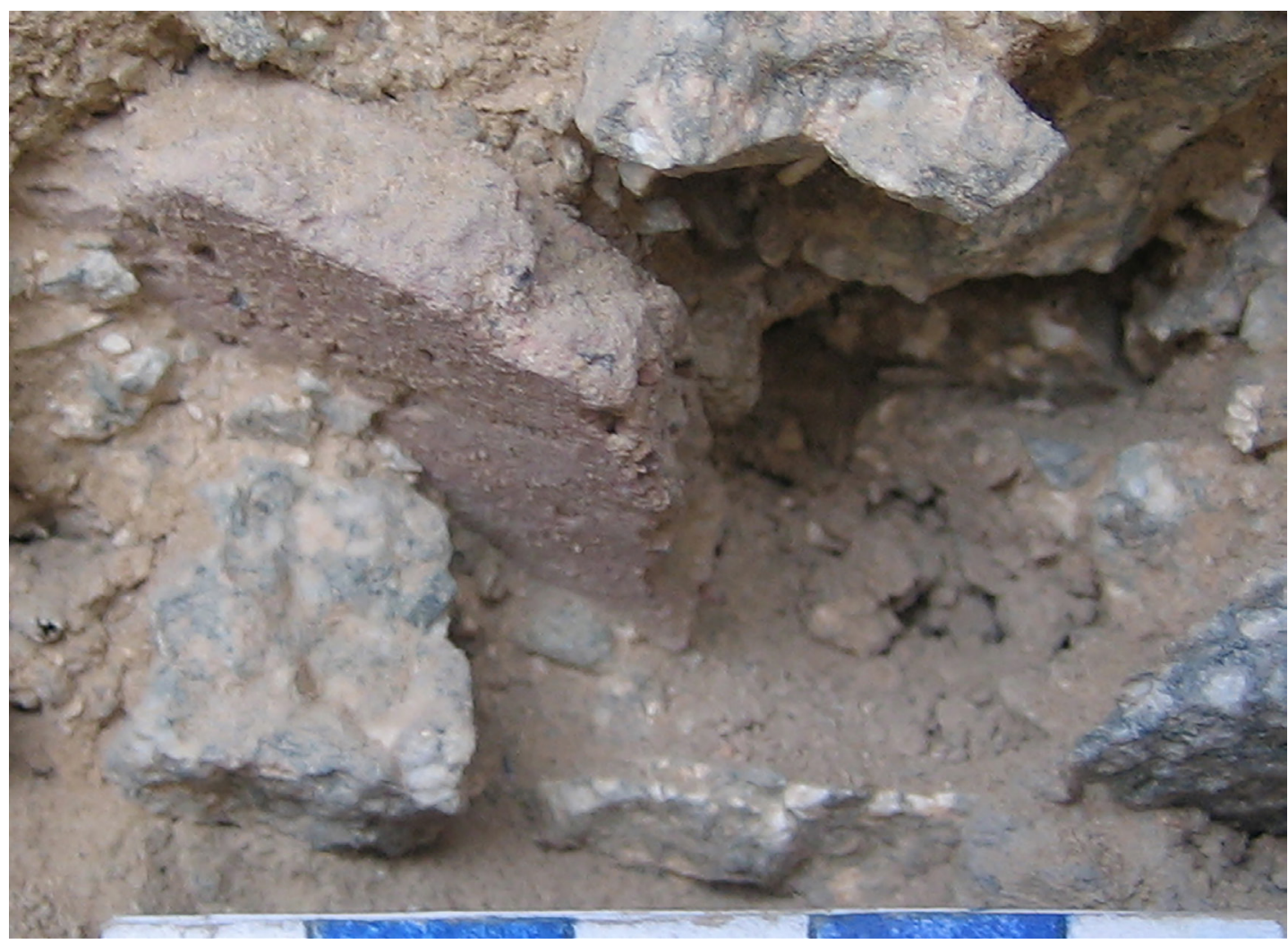

Figura 20. Vista de fragmento de cerámica incrustado en el mortero de la EA 1.

View of a ceramic sherd set in mortar at EA 1.

\section{Referencias Citadas}

Abrams, E.M. 1989. Architecture and energy: An evolutionary perspective. En Archaeological Method and Theory, Vol 1, editado por M.B. Schiffer, pp. 47-87. The University of Arizona Press, Tucson.

Álvarez, A. y J. Espinoza 1997. Mandinga. Un asentamiento tipo Aldas en el valle de Huarmey. Mauq'a Llaqta 1:27-89.

Ascencios, R. 2009. Investigaciones de las Shicras en el sitio precerámico de Cerro Lampay. Tesis de Licenciatura. Universidad Nacional Mayor de San Marcos, Lima.

Bazán, A. 2010. El Castillo de Huaricanga, un Sitio Formativo en el Valle de Fortaleza. Revista de Investigaciones del Centro de Estudiantes de Arqueología UNMSM 7:17-53.

Burger, R.L. 1992 Chavin and the Origins of Andean Civilization. Thames and Hudson. London.

Burger, R.L. 2009. Los Fundamentos sociales de la arquitectura monumental del Período Inicial en el Valle de Lurín. En Arqueología del Período Formativo en la Cuenca Baja de Lurín, editado por R. Burger y K. Makowski, pp. 17-36. Pontificia Universidad Católica del Perú, Lima.

Dietler, M. 2001 Theorizing the Feast. Rituals of Consumption, Comensal Politics, and Power in African Contexts. En Feasts. Archaeological and Ethnographic Perspectives on Food, Politics and Power, editado por M. Dietler y B. Hayden, pp. 65-114. Smithsonian Institution Press, Washington D.C.

Ferguson. T.J. 1996. Historic Zuni Architecture and Society An Archaeological Application of Space Syntax. Anthopological Papers of the University of Arizona. The University of Arizona Press, Tucson.

Fuchs, P., R. Patzschke, G. Yenquec y J. Briceño 2010. Del Arcaico Tardío al Formativo Temprano: las investigaciones en Sechín bajo, valle de Casma. Boletín de Arqueología PUCP 13:55-86.

Fung, R. y C. Williams 1977. Exploraciones y Excavaciones en el Valle de Sechín, Casma. Revista del Museo Nacional XLIII:111-155.

Gloag, J. 1975 The Architectural Interpretation of History. Adams \& Charles Black, London.

Haas, J. 1987. The Exercise of Power in Early Andean State Development. En The Origins and Development of the Andean State, editado por J. Haas, S. Pozorski y T. Pozorski, pp. 31-35. Cambridge University Press, Cambridge.

Haas, J., W. Creamer y Á. Ruiz 2004. Dating the Late Archaic occupation of the Norte Chico Region in Peru. Nature 432:1020-1023.

Hall, E. 1969. The Hidden Dimension. Anchor Books, New York. 
Hawass, Z y M. Lehner 1997. Builders of the Pyramids. Archaeology 50:31-37.

Hillier, B. y J. Hanson 1984. The Social Logic of Space. Cambridge University Press, Cambridge.

Huapaya, C. 1977. Vegetales como elemento antisísmico en estructuras prehispánicas. Arqueología PUCP 19-20:27-38.

Ishida, E. 1960. Andes. The Report of the University of Tokyo Scientific Expedition to the Andes in 1958. The University of Tokyo Press, Tokyo.

Kaulicke, P. 1994. Los Orígenes de la Civilización Andina. Arqueología del Perú. Historia General del Perú, Vol 1, J.A. Del Busto, general editor. Brasa, Lima.

Kaulicke, P. 2010. Las Cronologías del Formativo. 50 Años de Investigaciones Japonesas en Perspectiva. Pontificia Universidad Católica del Perú, Lima.

Kosok, P. 1965. Life, Land and Water in Ancient Peru. Long Island University Press, New York.

Lumbreras, L.G. 1969. De los Pueblos, las Culturas y las Artes del Antiguo Perú. Moncloa Campodónico, Lima.

Lumbreras, L.G. 1989. Chavin de Huántar en el Nacimiento de la Civilización Andina. Instituto Andino de Estudios Arqueológicos, Lima.

Moore, J. 1996. Architecture and Power in the Ancient Andes. The Archaeology of Public Buildings. Cambridge University Press, Cambridge.

Moseley, M.E. 1975. Prehistoric principles of labor organization in the Moche Valley, Peru. American Antiquity 40:191-196.

Nielsen, A. 1995. Architectural performance and the reproduction of social power. En Expanding Archaeology, editado por J. Skibo, W. Walker y A. Nielsen, pp. 47-66. University of Utah Press, Salt Lake City.

Onuki, Y. 1999. El período Arcaico en Huánuco y el concepto del Arcaico. Boletín de Arqueología PUCP 3:325-333.

Pizzo, A. 2009. La Arqueología de la Construcción. Un laboratorio para el análisis de la arquitectura de época romana. Arquitectura de la Arqueología 6:31-45.

Pozorski, S. 1987. Theocracy vs. militarism: The significance of the Casma Valley in understanding Early State formation. En The Origins and Development of the Andean State, editado por J. Haas, S. Pozorski y T. Pozorski, pp. 15-30. Cambridge University Press, New York.

Pozorski, S. y T. Pozorski 1987. Early Settlement and Subsistence in the Casma Valley, Peru. Iowa Press, Iowa City.

Pozorski, S. y T. Pozorski 1998. La Dinámica del Valle de Casma durante el Período Inicial. Boletín de Arqueología PUCP 2:83-100.

Pozorski, T. 1980. The Early Horizon Site of Huaca de los Reyes. Societal Implications. Américan Antiquity 45:100-110.

Rapoport, A. 1990. The Meaning of the Built Environment. The University of Arizona Press, Tucson.

Ravines, R. 1979. Garagay como Arqueología Experimental. En Arqueología Peruana, editado por R. Matos, pp. 75-80. Universidad Nacional Mayor de San Marcos, Lima.
Ruiz, Á., W. Creamer y O. Haas 2007. Investigaciones Arqueológicas en los Sitios del Arcaico Tardío (3000 a 1800 a.C.) del Valle de Pativilca, Perú. Instituto Cultural Norte Chico, Lima.

Sanders, D. 1990. Behavioral conventions and archaeology: Methods for analysis of ancient architecture. En Domestic Architectura and the Use of Space, editado por S. Kent, pp. 43-69. Cambridge University Press, Cambridge.

Segura, R. 2001. Rito y Economía en Cajamarquilla. Pontificia Universidad Católica del Perú, Lima.

Shady, R. 2001. La Ciudad Sagrada de Caral-Supe y los Orígenes de la Civilización Andina. Museo de Arqueología y Antropología de la Universidad Nacional Mayor de San Marcos, Lima.

Shady, R., C. Dolorier T., F. Montesinos y L. Casas S. 2000. Los orígenes de la civilización en el Perú: El Area Norcentral y el Valle de Supe durante el Arcaico Tardío. Arqueología y Sociedad 13:13-48.

Shady, R. y C. Leyva (eds.) 2003. La Ciudad Sagrada de Caral-Supe. Los Orígenes de la Civilización Andina y la Formación del Estado Prístino en el Antiguo Perú. Instituto Nacional de Cultura, Lima.

Shady, R., M. Machacuay, D. Cáceda, A. Crispín, Edna Quispe y P. Novoa 2009. Caral. La Civilización más Antigua de las Américas: 15 Años Develando su Historia. Zona Arqueológica de Caral, Lima.

Shady, R., M. Machacuay, P. Novoa, E. Quispa y C. Leyva 2016. Centros Urbanos de la Civilización Caral: 21 Años Recuperando la Historia sobre el Sistema Social. Zona Arqueológica de Caral, Lima.

Tello, J.C. y T. Mejía Xesspe 1956. Arqueología del Valle de Casma. Universidad Nacional Mayor de San Marcos, Lima.

Trigger, B.G. 1990. Monumental architecture: A thermodynamic explanation of symbolic behaviour. World Archaeology 22:119-132

Uhle, M. 1925. Report on explorations at Supe. En The Uhle Pottery Collections from Supe, editado por A.L. Kroeber. University of California Publications in American Archaeology and Ethnology 21(6):257-263.

Vega-Centeno, R. 2004. Arquitectura pública del Arcaico Tardío en el Valle de Fortaleza. reflexiones sobre las sociedades complejas tempranas en la Costa Nor Central. Arqueología y Sociedad 15:1-26.

Vega-Centeno, R. 2005a. Ritual and Architecture in a Context of Emergent Complexity. A Perspective from Cerro Lampay, a Late Archaic Site in the Central Andes. Tesis Doctoral. The University of Arizona, Tucson.

Vega-Centeno, R. 2005b. Consumo y ritual en la construcción de espacios públicos para el Periodo Arcaico Tardío: el caso de Cerro Lampay. Boletín de Arqueología PUCP 9:91-121.

Vega-Centeno, R., L.F. Villacorta, L.E. Caceres y G. Marcone 1998. Arquitectura monumental temprana en el Valle Medio de Fortaleza. Boletin de Arqueologia PUCP 2:219-238.

Willey, G.R. y J.M. Corbett 1954. Early Ancón and Early Supe Culture. Columbia University Press, New York. 
Williams, C. 1980. Arquitectra y urbanismo en el Antiguo Perú. En Historia del Perú, Vol. 8:369-585. J. Mejía Baca, editor general. Mejía Baca, Barcelona.

Williams, C. y F. Merino1979. Inventario, Catastro y Delimitación de Lugares Arqueológicos en el Valle de Supe. Manuscrito en los Archivos del Instituto Nacional de Cultura, Lima.
Wills, W.H. 2000. Political leadership and the construction of Chaco an Great Houses, A.D. 1020-1140. En Alternative Leadeship Strategies in the Prehispanic Southwest, editado por B.J. Mills, pp. 19-44. The University of Arizona Press, Tucson.

\section{Notas}

1 Suscribimos para la definición la propuesta de Onuki (1999), que considera como Formativo Inicial a aquellas expresiones culturales que florecieron entre los años 2500 a 1800 a.C. y que han sido usualmente consideradas como del Precerámico Tardío o Arcaico Tardío (entre las que destacan los sitios de Kotosh, El Paraíso, Caral o La Galgada), en tanto que son ya parte de los procesos de complejización social que van a caracterizar a los Andes Centrales.

2 Debe rescatarse el trabajo singular de Ravines (1979) con relación a procesos constructivos en el sitio de Garagay.
3 El sitio es comúnmente conocido como Cerro Blanco. Ha sido definido como Cerro Blanco Sur para distinguirlo de otros dos conjuntos arquitectónicos existentes en el anexo Cerro Blanco, definidos como Cerro Blanco Norte y Cerro Blanco Centro (Vega-Centeno 2004:37-38).

4 El término pachilla es usado en el área central andina para identificar a las piedras pequeñas que suelen colocarse entre piedras grandes y el mortero para consolidar la solidez e impermeabilidad de los muros. 
